Florida International University FIU Digital Commons

\title{
Workplace accommodations : potential moderators of perceived fairness
}

Veronica Wenette Averhart

Florida International University

DOI: $10.25148 /$ etd.FI14032374

Follow this and additional works at: https://digitalcommons.fiu.edu/etd

Part of the Psychology Commons

\section{Recommended Citation}

Averhart, Veronica Wenette, "Workplace accommodations : potential moderators of perceived fairness" (2008). FIU Electronic Theses and Dissertations. 1341.

https://digitalcommons.fiu.edu/etd/1341

This work is brought to you for free and open access by the University Graduate School at FIU Digital Commons. It has been accepted for inclusion in FIU Electronic Theses and Dissertations by an authorized administrator of FIU Digital Commons. For more information, please contact dcc@fiu.edu. 


\section{FLORIDA INTERNATIONAL UNIVERSITY}

Miami, Florida

WORKPLACE ACCOMMODATIONS: POTENTIAL MODERATORS OF PERCEIVED FAIRNESS

A thesis submitted in partial fulfillment of the requirements for the degree of

MASTER OF SCIENCE

in

PSYCHOLOGY

by

Veronica Wenette Averhart

2008 
To: Dean Kenneth Furton

College of Arts and Sciences

This thesis, written by Veronica Wenette Averhart, and entitled Workplace Accommodations: Potential Moderators of Perceived Fairness, having been approved in respect to style and intellectual content, is referred to you for judgment.

We have read this thesis and recommend that it be approved.

Leslie DeChurch

Nathan Hiller

Chockalingam Viswesvaran, Major Professor

Date of Defense: March 26, 2008

The thesis of Veronica Wenette Averhart is approved.

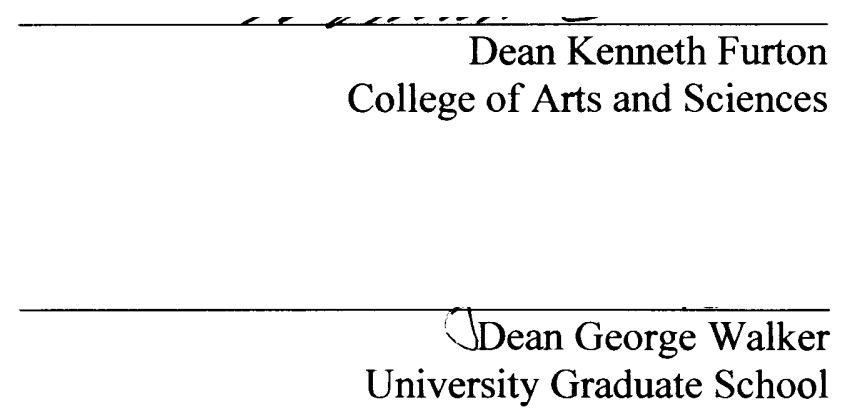

Florida International University, 2008 
(C) Copyright 2008 by Veronica Wenette Averhart

All rights reserved. 


\section{DEDICATION}

I dedicate this thesis to the memory of my mother, Carma Averhart. Her passion for knowledge and continual self-improvement inspire me everyday. It is my hope that through my life adventures and academic endeavors I can make her proud and carry on her legacy. 


\section{ACKNOWLEDGMENTS}

I would like to thank all of my committee members for their guidance, patience,

and support. It is with their leadership that I was able to complete this project. Dr. Leslie DeChurch was particularly helpful during the determining of appropriate statistical analyses. Dr. Nathan Hiller reminded me to think creatively and assisted me in the finetuning of the business summaries used in this study. Last, but not least, my major professor, Dr. Chockalingam Viswesvaran, helped me to develop my skills as a writer and a researcher. His mentorship has provided me with knowledge and skills that I will be able to use throughout my life.

I would also like to thank all of my family for their love and support. I am especially appreciative of my father, Vernon Averhart, who has been a consistent source of encouragement throughout this process. 


\section{ABSTRACT OF THE THESIS \\ WORKPLACE ACCOMMODATIONS: POTENTIAL MODERATORS OF \\ PERCEIVED FAIRNESS \\ by}

Veronica Wenette Averhart

Florida International University, 2008

Miami, Florida

Professor Chockalingam Viswesvaran, Major Professor

This study examined variables that may influence coworkers' acceptance of

accommodations made for employees with disabilities. Agreeableness, conscientiousness, emotional stability, self-esteem, and emotional intelligence were predicted to affect the relationship between procedural justice and fairness perceptions of accommodations made for disabled workers. Approximately 400 university students read one of four accommodation scenarios and provided fairness ratings in order to test eight hypotheses. Results provided evidence that the presence of procedural justice had a direct influence on participants' fairness perceptions of implemented accommodations. Participants' individual characteristics were also directly related to fairness perceptions. Additionally, conscientiousness was found to moderate the relationship between the presence of procedural justice and fairness perceptions. Findings from this study suggest that organizations should use clear and consistent guidelines and procedures to determine and implement accommodations. Additionally, findings reinforce the importance of keeping individuals informed of the ways in which decisions are made within an organization. 


\section{TABLE OF CONTENTS}

CHAPTER

PAGE

I. INTRODUCTION ...................................................... 1

Disabilities in the United States ........................................ 2

Americans with Disabilities Act.......................................... 3

II. LITERATURE REVIEW .............................................. 7

Justice Theories....................................................... 7

Nature of the Disability ............................................ 11

Individual Difference Characteristics of Non-disabled Coworkers ............... 15

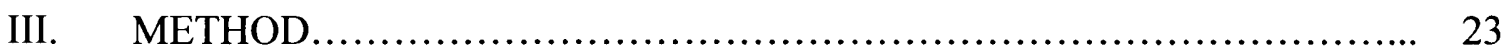

Participants........................................................... 23

Procedure............................................................... 24

Manipulations.......................................................... 27

Measures............................................................. 29

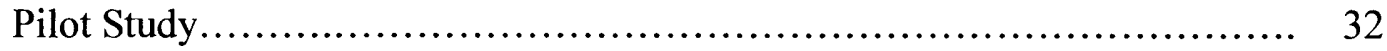

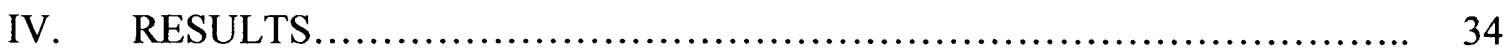

Manipulation Checks................................................ 35

Hypothesis Testing.................................................... 35

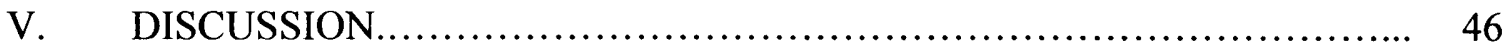

Investigation of Main Effects......................................... 47

Alternative Explanations............................................... 50

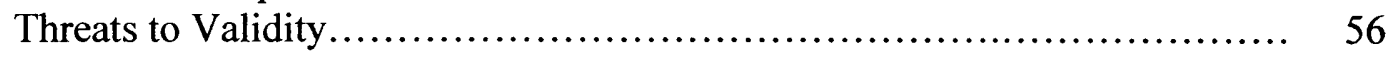

Future Research...................................................... 58

Implications and Conclusion.......................................... 59

REFERENCES.......................................................... 60

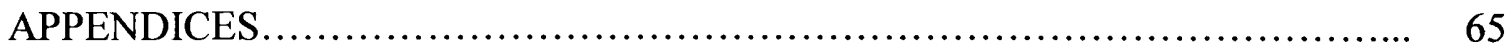




\section{LIST OF TABLES}

TABLE

1. Descriptive Statistics and Frequencies for Participant Characteristics.................... 25

2. Intercorrelations Between Individuals Characteristics and Fairness Perceptions.... 34

3. Mean Fairness Ratings for Each Condition................................. 37

4. Hierarchical Regression Analyses for Agreeableness Predicting Fairness Perceptions.

5. Hierarchical Regression Analyses for Conscientiousness Predicting Fairness Perceptions.

6. Hierarchical Regression Analyses for Emotional Stability Predicting Fairness Perceptions.

7. Hierarchical Regression Analyses for Self-esteem Predicting Fairness Perceptions.

8. Hierarchical Regression Analyses for Emotional Intelligence Predicting Fairness Perceptions. 


\section{Chapter I: Introduction}

Currently, organizations are making great efforts to employ individuals who reflect the diversity of the greater society. Individuals from historically underrepresented groups, including women and ethnic minorities, are being hired at greater rates and have more opportunities for advancement within organizations. Despite this push for diversity in the corporate arena, individuals from one of the largest minority groups, persons with disabilities, have not been positively affected (U.S. Census Bureau, Systems Support Division, 2000). A disability refers to “any long- or short-term reduction of a person's activity as a result of a chronic condition" (Stoddard, Jans, Ripple, \& Kraus, 1998, p. 51). Although in the United States there are currently 41.6 million persons with disabilities that are of working age (fifteen to sixty-four), only $35.1 \%$ are employed. In contrast $84.7 \%$ of the 70.4 million working aged individuals without disabilities are employed. These figures indicate that there is almost a $50 \%$ disparity in unemployment rates for individuals with disabilities versus individuals without disabilities (U. S. Bureau of the Census, Systems Support Division, 2000).

Individuals with disabilities face special challenges when seeking employment. Employers often have reservations about hiring persons with disabilities because of their perceptions of the costs of accommodations and the perceived decreased likelihood of these persons being promoted (McFarlin, Song, \& Sonntag, 1991). Furthermore, problems do not end once disabled individuals gain employment. This population often experiences many difficulties at work, including being placed in low level jobs, receiving a lower pay than their non-disabled counterparts, and not having close relationships with their coworkers (Stone-Romero, Stone, \& Lukaszewski, 2006). 
In a business world with an increased emphasis on teamwork, it is critical that coworkers are able to work well with each other. The development of this relationship may be challenging due to able-bodied coworkers' difficulties relating to their disabled team members. In addition, some employees with disabilities who receive special accommodations may be perceived as having unfair advantages by their coworkers. These perceptions of accommodations, whether fair or not, influence the way in which they treat employees with disabilities. Able-bodied employees who perceive accommodations to be fair may view these accommodations as necessary aids rather than as unfair advantages. Furthermore, coworkers often play a role in the successful implementation of accommodations for the disabled. When coworkers perceive accommodations to be fair, they will be more willing to assist in the implementation of those accommodations (Colella, 2001).

\section{Disabilities in the United States}

According to Stoddard et al. (1998), there are currently two classifications of disabilities, severe and non-severe. The U. S. Census Bureau classifies individuals aged fifteen or older as having a severe disability if they meet at least one of the following criteria: 1) they find it difficult to perform activities related to functioning; 2) they require personal assistance in order to complete activities of daily living (ADL) or instrumental activities of daily living (IADL); 3) they use a wheelchair; 4) they are a long-term user of a cane, a walker, or crutches; 5) they have a developmental disability or Alzheimer's disease; 6) they are unable to complete household chores; 7) they are currently receiving disability benefits from the federal government; or 8) they are between the ages of sixteen and sixty-seven years old and are not able to work at a job or business. Individuals with a 
severe disability between the ages of twenty-one and sixty-four have a $26.1 \%$ chance of having a job or business, while individuals without a disability have an $82.1 \%$ average likelihood of having a job or business (Stoddard et al., 1998).

The U. S. Census Bureau defines a non-severe disability as an acute or chronic pain that reduces an individual's daily functioning, but does not meet any of the criteria for a severe disability. For example, a person with a non-severe disability may find it physically difficult to perform household chores, but they are still able to complete them. Individuals with a non-severe disability between the ages of twenty-one and sixty-four have a $76.9 \%$ average chance of having a job or business. This is in contrast to individuals without a disability between the ages of twenty-one and sixty-four who have an $82.1 \%$ likelihood of being employed or having a business (Stoddard et al., 1998). In 1990 , legislation was put into place to protect individuals with disabilities from experiencing the discriminatory practices that contribute to their lower rates of employment. This legislation, referred to as the Americans with Disabilities Act, is discussed in the following section.

Americans with Disabilities Act

The Americans with Disability Act (ADA) was created in 1990 to prevent "private employers, state and local governments, employment agencies and labor unions from discriminating against qualified individuals with disabilities in job application procedures, hiring, firing, advancement, compensation, job training, and other terms, conditions, and privileges of employment" (U. S. Equal Employment Opportunity Commission, 2006). In addition, the ADA requires that employers handle each accommodation request by applicants and employees with disabilities on a case by case 
basis (Colella, Paetzold, \& Belliveau, 2004). The guidelines of the ADA apply to organizations with at least fifteen employees. Only individuals with a disability who are able to perform essential requirements of the job without the assistance of an accommodation are eligible to receive an accommodation (U.S. Equal Employment Opportunity Commission, 2006). Accommodations provided by the ADA include, but are not limited to, adjustments in the tools used for work, the location in which work takes place, the availability of valuable commodities, the duties required of employees, the physical conditions of the work, and the resources that are available to coworkers (Colella, 2001).

In addition to providing protection for employees with disabilities, the ADA provides protection for organizations. Employers are not required to provide accommodations that impose an undue hardship for the organization. An undue hardship is "an action requiring significant difficulty or expense when considered in light of factors such as an employer's size, financial resources, and the nature and structure of its operation" (U. S. Equal Employment Opportunity Commission, 2006). Also, the ADA does not call for employers to lower their standards of production in order to provide accommodations. The ADA places restrictions on the types of accommodations that an organization is required to provide. Employers are not, for example, required to provide items that could be used at home, such as hearing aids or glasses (U.S. Equal Employment Opportunity Commission, 2006).

Although accommodations provided by the ADA are meant to create a more hospitable environment for workers with disabilities, they can actually foster resentment among coworkers. Coworkers' resentment may be a result of their perception of 
accommodations representing preferential treatment or unfair advantages rather than necessary aid (Colella, 2001).

This study sought to build on previous research by examining variables that influence perceived fairness and variables that moderate the relationship between justice theories and perceived fairness. This study specifically looked at perceived fairness of accommodations for employees with disabilities. Several theories about the rules that people use to make fairness judgments have been proposed. In this study, the theory of procedural justice was used as the framework for judgments about outcomes. Several individual characteristics, including agreeableness, conscientiousness, emotional stability, self-esteem, and emotional intelligence were examined.

While results from previous studies offer a foundation for understanding the relationship between procedural justice and perceptions of fairness, there remain other areas which warrant investigation. For example one possible area of research is the importance of procedural justice in accommodation settings, and whether organizations should take special care that the policies and procedures for employees with disabilities are reflective of this. Furthermore, do individual characteristics lead individuals to be more accepting of accommodations, regardless of the presence of procedural justice, and can organizations assess these characteristics during their selection process? This study sought to provide insight into variables associated with the successful integration of individuals with disabilities into the workforce, as well as foster ideas for future research. The following chapter provides an overview of current justice theories with an emphasis on procedural justice, the impact of the nature of disabilities on people's perceptions of 
individuals with disabilities, and potential moderators of the relationship between procedural justice and perceptions of fairness. 


\section{Chapter II: Literature Review}

Justice Theories

Relative Deprivation. Relative deprivation refers to people's tendency to make judgments about the quality of their outcomes by comparing them to the outcomes of others around them. Sometimes people use their previous experiences or expectations of the future in order to assess their current situations. In these circumstances, people have more positive reactions to unfavorable outcomes when they compare their current self to a past or future self that is in a worse circumstance. At other times people compare their outcomes to the outcomes of similar individuals in slightly better situations (Tyler \& Smith, 1998).

Distributive Justice. The first and main model of distributive justice, equity theory (Adams, 1965), states that people's reactions to outcomes, both emotional and physical, are based on the outcomes determined to be fair. The justice rule states that inputs and outputs should be balanced with each other such that a person's outcome reflects their level of input (Tyler \& Smith, 1998). Individuals who do not believe that they have received what they deserve will feel distress. Some individuals will feel angry for receiving too little. Other individuals will feel guilty for receiving too much (Adams, 1965). Feelings of anger or guilt will motivate individuals to take the necessary actions in order to correct the discrepancies in outcomes and lessen these feelings (Tyler \& Smith, 1998).

Equity is not the only principle used in distributive justice to determine the fairness of outcomes. Other principles such as, equality or need, are also used to determine the fairness of outcomes. The goals of interpersonal interactions dictate the 
principles used to determine fairness. When economic productivity is the goal of interpersonal interactions, equity is used to determine the fairness of outcomes. Equality is used in situations in which nurturing or maintaining social relations is the main goal of the interpersonal interaction. When the fostering of personal development and personal welfare is the main goal of the interpersonal interaction, need is used to determine the fairness of outcomes (Deutsch, 1975).

Retributive Justice. Retributive justice refers to an individual's reaction to behaviors that break the rules. Retributive justice addresses several issues including, when punishment is warranted, the appropriate type of punishment, and the appropriate severity of the punishment. When a rule is broken, people want rule-breakers to be punished rather than only having equity restored. The severity of the discretion often dictates the severity of the punishment. Once deemed necessary, punishment is carried out through informal and/or formal measures (Tyler \& Smith, 1998).

Procedural Justice. Procedural justice refers to the idea that people make judgments about the fairness of the procedures used to determine the distribution of rewards and resources. People generally use six justice rules to assess the fairness of decision-making procedures. The first rule, consistency, refers to the uniformity of procedures across people and time. Consistency across people refers to the importance of treating everyone affected by the decision equally. Consistency across time is defined as using the same procedures each time the specific situation arises. Furthermore, consistency across time takes into consideration the importance of being careful when changing procedures and notifying all individuals who may be affected by the changes. The second rule, bias suppression, focuses on the ability of the procedure to prevent the 
opportunity for personal interests and biases to affect the decisions made. When procedures are able to suppress personal biases, they allow decision-makers to consider all viewpoints equally and adequately. The third rule, accuracy, ensures that decisions are made using the accurate information and opinions of experts or well informed individuals. The fourth rule, correctability, incorporates a method that allows decisionmakers to modify or correct decisions that have been made. The fifth rule, representativeness, calls for decision-makers to take the values, concerns, and outlook of those affected by decisions into consideration at all times of the decision-making process. In addition, this rule allows individuals affected by the decision to influence the process and share their opinions. The sixth rule, ethicality, is the alignment of procedures with moral standards and ethical values. Procedures that do not meet these standards should not be used regardless of their perceived benefits (Myyry \& Helkama, 2002). The combination of these six justice rules allows people to assess the justness of procedures used.

Similar to the principles of equity, equality, and need used in distributive justice, the six rules of procedural justice demonstrate that several factors are used to assess the fairness of decisions. People do not base their perceptions of the fairness of decisions on only one justice rule; rather, they use a combination of the rules to come to their fairness conclusions. Unlike the trade-offs made among the principles used in distributive justice, trade-offs are not made among the six procedural justice rules. In distributive justice, the goal of the interpersonal interaction dictates the principle that is used. In procedural justice, all six justice rules are utilized in most situations. Generally, this lack of tradeoffs results in procedures receiving similar ratings among the six rules. For example, a 
procedure that receives a high rating for consistency will generally receive a high rating for bias suppression as well (Tyler, 1988). Although trade-offs are not made among the six justice rules, differential weights of importance may be given to each justice rule. Consistency, accuracy of information, and ethicality have been found to be given the greatest weight when measuring procedural justice (Barrett-Howard \& Tyler, 1986; Lind \& Tyler, 1988).

In addition to influencing individuals' satisfaction with decisions made, the presence of procedural justice also plays a role in determining how individuals react to certain social policies, such as the accommodations provided by the ADA (Nacoste, 1987). Reactions to social policies include job satisfaction ratings (Greenberg, 1988), levels of commitment to the organization (Folger \& Konovsky, 1989), job performance levels (Lind, Kanfer, \& Earley, 1990), and organizational citizenship behaviors (Moorman, 1991). Coworkers' positive reactions to accommodations are critical because of the important role they play in the successful implementation of those accommodations (Colella, 2001). For instance, some accommodations require changes in scheduling or work duties of workers who are not eligible to receive such accommodations. These types of changes require coworkers' acceptance and assistance. Based on the nature of procedural justice it was anticipated that accommodations made using procedural justice rules would be considered fairer than accommodations made without using procedural justice rules.

Hypothesis 1: Mean fairness perceptions of accommodations made using the six procedural justice rules will be higher than mean fairness perceptions of accommodations made without using the six procedural justice rules. 
This study used the procedural justice framework as a foundation for individuals' perceptions of fairness, but also took into consideration the effect of both the nature of the disability and individual differences. The nature of an individual's disability will be discussed in the next section.

Nature of the Disability

It is human nature for people to place other individuals into categories and to treat them according to these categories. The gender, race, social status, nature of the disability, and previous performance level of individuals with disabilities affects the categories in which they are placed. This categorization in turn influences the job-related attributes, performance expectancies, and treatment experienced by individuals with disabilities in an organization (Stone \& Colella, 1996). The nature of an individual's disability is thought to be the main influence on the ways in which they will be perceived, categorized, and subsequently treated by others. These categorizations are based on salient physical features or social cues (Brewer \& Kramer, 1985). Previous research has found that some types of disabilities receive more negative reactions from people than other types of disabilities. Goldstein and Blackman (1975) found that individuals with physical disabilities were viewed more positively than individuals with psychological and sensory disorders, and these individuals were viewed more positively than individuals suffering from chemical dependencies.

Disabilities vary along six dimensions; aesthetic qualities, origin, course, concealability, disruptiveness, and danger. These six dimensions are used by people to further classify individuals with disabilities (Jones, Farina, Hastorf, Markus, Miller, Scott, \& De Sales-French, 1984). 
Aesthetic qualities describe the ways in which some disabilities negatively affect people's outward appearance (Jones et al., 1984). A model by Stone, Stone, and Dipboye (1992) hypothesizes that people have more negative reactions to individuals with disabilities that negatively impact their physical appearance. This suggests that individuals with disabilities that affect their physical appearance will be considered undesirable and receive more negative treatment (Stone \& Colella, 1996).

Origin refers to the perceived responsibility a person has for their disability. People react differently towards individuals with disabilities when they perceive that the person had some part in their disability as opposed to those perceived to have a disability that was beyond their control (Jones et al., 1984). These perceptions affect the ways in which people relate to individuals with disabilities. Research by Weiner, Perry, and Magnusson (1988) supports this idea. They examined individuals' perceptions about the correctability and stability of the causes of ten different stigmas. They found that people who perceived physically-based stigmas as onset-uncontrollable experienced feelings of pity and a desire to help. This was in contrast to mental-behavioral stigmas that were perceived as onset-controllable and resulted in feelings of anger, blame, and judgments to neglect.

Course refers to the permanence or reversibility of a disorder. Some disabilities, such as a broken limb or a first degree burn, are temporary or reversible. Other disabilities, such as blindness or multiple sclerosis, are permanent and irreversible (Jones et al., 1984). 1t is suggested that individuals with more progressive and irreversible disabilities will be classified as undesirable and receive more negative affective responses from others (Stone \& Colella, 1996). Research by Meyerowitz, Williams, and Gessner 
(1987) that examined people's reactions to a single disease that received two different labels supports the idea that people react differently to disabilities dependent on their permanence or reversibility. Participants were asked to read and give reactions to a paragraph that described a single disease that was referred to as either cancer or the fictitious disease, Haltmar's Disease. They found that participants had more positive reactions to the disease when it was referred to as cancer rather than Haltmar's Disease. In addition, participants gave more positive ratings when they perceived the disease as controllable as opposed to uncontrollable.

Concealability describes the ease in which the disability can be detected by others or hidden from others (Jones et al., 1984). Stone and Colella (1996) hypothesized that people will place visible disabilities in more negative categories and will display more negative affective reactions. Previous research supports these hypotheses. Gouvier, Steiner, Jackson, Schlater, and Rain (1991) examined the impact of neurological causation, handicap visibility, and degree of public contact on simulated employment decisions for individuals with disabilities. Researchers found that participants gave lower ratings to individuals with neurologically based or more visible disabilities.

Disruptiveness refers to "the extent to which the condition or disability interferes with the flow of communication or causes strain and uncertainty in social interaction" (Jones et al., 1984). Stone and Colella (1996) hypothesized that highly disruptive disabilities will be placed into more negative categories and receive more negative affective reactions. These negative reactions may be a result of the anxiety felt by nondisabled individuals when they are in situations that involve interaction with individuals with highly disruptive disabilities (Stone \& Colella, 1996). 
Danger or peril refers to individuals' perceptions that they could be harmed by or actually catch a disability from others (Jones et al., 1984). When people perceive a disability to be harmful to them, they will categorize it more negatively and react more negatively to individuals with these types of disabilities. In addition, the more dangerous or contagious that the disability is, the more negatively a person with this disability will be perceived (Stone \& Colella, 1996).

The results from these studies on the six dimensions of disabilities seem to imply that the nature of the disability influences the ways in which a disabled employee is perceived and subsequently categorized. This study specifically examined how the type of disability affects individuals' perceptions of the disabled employee and subsequent perceived fairness of the accommodation provided to this employee. Based on the findings of Weiner, Perry, and Magnusson (1988), it was anticipated that the onset of a physical disability would be perceived as more uncontrollable than a mood disorder and result in higher perceptions of fairness for accommodations made for employees with physical disabilities. Additionally, it was expected that the type of disability would affect the relationship between the presence of procedural justice and fairness perceptions of accommodations made for employees with disabilities.

Hypothesis 2: Mean perceptions of fairness will be higher for accommodations made for individuals with physical disabilities versus accommodations made for individuals with mood disorders.

Hypothesis 3: The presence of procedural justice and type of disability will interact to influence perceptions of fairness, such that the procedural justice- 
fairness perceptions link will be stronger in evaluating individuals with a psychological disorder than for those with a physical disability.

As discussed in the previous two sections, the presence of procedural justice and the nature of an individual's disability may influence the perceived fairness of accommodations made for disabled employees. Although these two variables are considered to have direct effects on perceptions of fairness, other variables may have a more indirect effect on perceptions of fairness. Variation in individual characteristics may moderate the relationship between procedural justice and perceptions of fairness. Specifically, agreeableness, conscientiousness, emotional stability, self-esteem, and emotional intelligence were of particular interest and will be discussed in the next section.

Individual Difference Characteristics of Non-disabled Coworkers

Agreeableness. Agreeableness, also referred to as likeability, describes individuals who exhibit qualities, such as friendliness, caring, and cooperativeness (Viswesvaran \& Ones, 2004). Individuals high in agreeableness are soft-hearted, trusting, and helpful, whereas, individuals low in agreeableness are ruthless, suspicious, and uncooperative (Myers, 2002). High levels of agreeableness are associated with the avoidance of conflict (Avery, 2003) and fewer displays of high emotion (Skarlicki, Folger, \& Tesluk, 1999).

As of yet, research has not been conducted to examine the moderating influence of agreeableness on the relationship between procedural justice and perceptions of fairness of accommodations. Some research, however, has examined the moderating influence of agreeableness on the relationship between perceptions of the work 
environment and organizational deviance. For instance, Skarlicki et al. (1999) examined how personality characteristics moderate the relationship between the presence of distributive and interactional justice. They found that agreeableness affected the power of the interaction between distributive and interactional justice to predict organization retaliatory behaviors. When agreeableness was high, the interaction between distributive and interactional justice was not a significant predictor of organization retaliatory behaviors. When agreeableness was low, the interaction between low levels of distributive and interactional justice was predictive of organization retaliatory behavior. In another study, Colbert, Mount, Harter, Witt, and Barrick (2004) examined how personality interacts with the relationship between perceptions of the work situation and workplace deviance. They found that even when people did not perceive organizational support, individuals high in agreeableness were least likely to take part in interpersonal deviance. The results of these studies seem to imply that individuals high in agreeableness may be naturally more inclined to perceive situations as fair and act accordingly. Consequently, it was anticipated that individuals high in agreeableness would perceive accommodations more fairly, regardless of the presence of procedural justice.

Hypothesis 4: The relationship between procedural justice and perceptions of fairness will be moderated by an individual's level of agreeableness, such that individuals low in agreeableness will give greater weight to the presence of procedural justice than individuals high in agreeableness.

Conscientiousness. Conscientiousness describes the amount of self-discipline and achievement-striving that an individual possesses (Barrick \& Mount, 1991). Individuals 
high in conscientiousness are organized, disciplined, and careful, whereas individuals low in conscientiousness are disorganized, impulsive, and careless (Myers, 2002). Highly conscientious individuals are more likely to set goals and be committed to achieving those goals, which results in the achievement of high levels of performance (Barrick, Mount, \& Strauss, 1993).

To date, there has been no research examining the moderating influence of conscientiousness on the relationship between procedural justice and perceptions of fairness of accommodations. Some work, however, has examined the moderating influence of conscientiousness on the relationship between procedural justice and perceptions of fairness of other organization procedures. In one such study, Dineen, Noe, and Wang (2004) examined the influence of conscientiousness on the relationship between procedural justice and perceptions of fairness of a Web-based applicant screening system. They found that conscientious individuals judged Web-based screening systems that contain elements of procedural justice to be fairer than Web-based screening systems that did not contain elements of procedural justice. Out of the six procedural justice rules, conscientious individuals valued consistency, correctability, and representativeness the most. The results of this study suggest that conscientious individuals value procedural justice more than unconscientious individuals. Conscientious individuals appear to place greater importance on procedural justice in the decision-making process due to the self-discipline and achievement-striving components of their character. Conscientious individuals may feel that there should be logical and consistent guidelines used to make decisions. Furthermore, conscientious individuals may be more concerned with how the decisions made would affect their own chances to 
achieve their personal goals. Therefore, it was anticipated that individuals high in conscientiousness would perceive accommodations more fairly when procedural justice is present.

Hypothesis 5: The relationship between procedural justice and perceptions of fairness will be moderated by an individual's levels of conscientiousness, such that individuals high in conscientiousness will give greater weight to the presence of procedural justice than individuals low in conscientiousness.

Emotional Stability. Emotional stability measures the constancy of an individual's emotions (Avery, 2003). Individuals high in emotional stability are calm, self-satisfied, and secure. Individuals low in emotional stability, or neurotic individuals, are anxious, self-pitying, and insecure (Myers, 2002). Neurotic individuals often find it difficult to adjust to changes in the work environment and typically react emotionally to workplace conflicts (Raymark, Schmit, \& Guion, 1997).

To date, little research has examined the moderating influence of emotional stability on the relationship between procedural justice and perceptions of fairness of accommodations. There is some work, however, examining the moderating influence of emotional stability on the relationship between features of a system and perceptions of the system. For instance, Zweig and Webster (2003) examined the ways in which personality influenced individuals' perceptions of workplace monitoring system characteristics. They found an interesting interaction: individuals low in emotional stability had more negative perceptions of monitoring systems than individuals high in emotional stability, even when the system had protections for privacy and fairness. The results of this study seem to imply that individuals low in emotional stability make 
judgments about a system based on the features of the system as well as their overall attitude towards the system. Consequently, it was anticipated that individuals low in emotional stability would perceive accommodations with procedural justice as fairer than accommodations without procedural justice.

Hypothesis 6: The relationship between procedural justice and perceptions of fairness will be moderated by an individual's level of emotional stability, such that individuals low in emotional stability will give greater weight to the presence of procedural justice than individuals high in emotional stability.

Self-esteem. Self-esteem measures an individual's feeling of overall self-worth (Harter, 1990). Individuals with high self-esteem are more likely to persevere through difficult situations and tasks, to take the initiative during group tasks, and to have positive feelings (Tafarodi \& Vu, 1997; Baumeister, Campbell, Krueger, \& Vohs, 2003). Individuals with low self-esteem are often unhappy and feel despair. Dependent on an individual's vulnerabilities towards depression and anxiety, low self-esteem may manifest itself in different ways. Individuals with low self-esteem and a vulnerability to depression do not feel that their reality matches what they had hoped for themselves. Individuals with low self-esteem and a vulnerability to anxiety do not feel that their lives or behaviors are at the levels that they should be (Myers, 2002).

Few studies have been conducted to examine the moderating influence of selfesteem on the relationship between procedural justice and perceptions of fairness of accommodations. There exists, however, some research which has investigated the moderating influence of self-esteem on the relationship between procedural justice and perceptions of fairness of other organization procedures. One study, for instance, 
Brockner, Heuer, Siegel, Wiesenfeld, Martin, Grover, Reed, and Bjorgvinsson (1998), examined the influence of self-esteem on the relationship between procedural justice and employee reactions to lay-off survival, cost-cutting, and interpersonal encounters. They found that individuals with high self-esteem had more positive reactions when procedural justice was present than when it was absent. When lay-off survivors were allowed to provide input, individuals with high self-esteem were more likely to stay with the organization than individuals with low self-esteem. Also, individuals with high organization-based self-esteem in cost-cutting situations had greater organizational identification when they perceived the opportunity to provide input. There was no relationship between perceived level of voice and organizational commitment for individuals with low organization-based self-esteem. Additionally, in interpersonal situations, the relationship between perceived level of voice and satisfaction was stronger for individuals with high self-esteem than individuals with low self-esteem. The results of this study imply that the presence of procedural justice is more important to individuals with high self-esteem than to those with low self-esteem. This difference may occur because individuals with high self-esteem are more likely than individuals with low selfesteem to place a greater value on themselves, feeling that they deserve to be treated fairly. Therefore, it was anticipated that individuals with high self-esteem would perceive accommodations with procedural justice as fairer than accommodations without procedural justice.

Hypothesis 7: The relationship between procedural justice and perceptions of fairness will be moderated by an individual's level of self-esteem, such that 
individuals with high self-esteem will give greater weight to the presence of procedural justice than individuals with low self-esteem.

Emotional Intelligence. Emotional intelligence describes "the set of abilities that accounts for how people's emotional reports vary in their accuracy and how better understanding of emotion leads to better problem solving in an individual's' emotional life" (Mayer, Salovey, \& Caruso, 2000). Individuals who are high in emotional intelligence are able to manage their own emotions, delay gratification, read and skillfully handle others' emotions, and effectively manage conflicts (Myers, 2002). Emotional intelligence is positively related to job satisfaction, personal effectiveness, organizational commitment, positive attitude about life, vertical trust, and organizational productivity. Emotional intelligence is negatively related to conditional continuance commitment and turnover intention (Sinha \& Jain, 2004).

The ability of emotionally intelligent individuals to read others' emotions may cause them to be more open to accommodations for coworkers' with disabilities. This acceptance may be a result of their greater understanding of the physical and emotional benefits of the accommodation. In addition, individuals high in emotional intelligence may feel more confident in their ability to handle any conflicts that may result from the accommodation. Emotionally intelligent individuals may place less importance on procedural justice because they are more concerned with the positive emotional impact that accommodations will have on their coworkers. Furthermore, individuals high in emotional intelligence may be more likely to overlook the possible increase in work that may result from the implementation of accommodations. Consequently, it was anticipated 
that individuals low in emotional intelligence would perceive accommodations with procedural justice as fairer than accommodations without procedural justice.

Hypothesis 8: The relationship between procedural justice and perceptions of fairness will be moderated by an individual's level of emotional intelligence, such that individuals low in emotional intelligence will give greater weight to the presence of procedural justice than individuals high in emotional intelligence. 


\section{Participants}

\section{Chapter III: Method}

A total of 408 individuals participated in this online study. Data was collected in four waves with each wave corresponding to one of the four conditions. Wave 1 was comprised of 95 individuals, 23 males and 72 females. Participants ranged in age from 18 to 56 with a mean age of 22.03 . The majority of participants identified themselves as being of Hispanic origin (77.9\%). Approximately $75 \%$ of participants were employed at their time of participation. Regarding their current contact with persons with disabilities, approximately $34 \%$ of participants reported having a relative or close friend that suffered from a disability.

Wave 2 was comprised of 100 individuals, 27 males and 73 females. Participants ranged in age from 18 to 53 years old with a mean age of 22.78 . The majority of participants identified themselves as being of Hispanic origin (72.0\%). Sixty-eight percent of participants were employed at their time of participation. Regarding their current contact with persons with disabilities, $35 \%$ of participants reported having a relative or close friend that suffered from a disability.

Wave 3 was comprised of 109 individuals, 30 males and 79 females. Participants ranged in age from 17 to 39 years old with a mean age of 20.86 . The majority of participants identified themselves as being of Hispanic origin (76.1\%). Approximately $63 \%$ of participants were employed at their time of participation. Regarding their current contact with persons with disabilities, approximately $34 \%$ of participants reported having a relative or close friend that suffered from a disability. 
Wave 4 was comprised of 104 individuals, 29 males and 75 females. Participants ranged in age from 17 to 32 with a mean age of 19.11 . The majority of participants identified themselves as being of Hispanic origin (71.2\%). Approximately $46 \%$ of participants were employed at their time of participation. Regarding their current contact with persons with disabilities, approximately $34 \%$ of participants reported having a relative or close friend that suffered from a disability.

The comparison between the four waves on four demographic characteristics (age, Hispanic origin, employment status, and close relationship with a person with a disability) indicated that among the groups there was a significant difference in employment status $\left(\chi^{2}(3, \mathrm{~N}=396)=18.61, \mathrm{p}<.01\right)$ and age $(\mathrm{F}(3,395)=12.14, \mathrm{p}<.01)$. Additionally, there was a significant negative correlation between employment status and age $(r=-.17, p<.01)$. As result of these findings, employment status was included as a covariate in all regression analyses, and age was included as covariate for analyses that only included employed participants. Also important to note is that other than employment and age, none of the control variables correlated with the key variable, procedural justice rules.

\section{Procedure}

Participants logged onto the online participant pool system to complete this online study. All participants received partial course credit once their questionnaire was submitted. Table 1 presents the descriptive statistics for each wave. 
Table 1

Descriptive Statistics and Frequencies for Participant Characteristics

\begin{tabular}{llllll}
\hline Wave & $\mathrm{N}$ & Mean Age & $\begin{array}{l}\text { Hispanic } \\
\text { Origin (\%) }\end{array}$ & $\begin{array}{l}\text { Employment } \\
(\%)\end{array}$ & $\begin{array}{l}\text { Disabled } \\
\text { Relative/Friend (\%) }\end{array}$ \\
\hline 1 & 95 & $\begin{array}{l}22.03 \\
(5.85)\end{array}$ & 77.9 & 74.7 & 33.7 \\
2 & 100 & $\begin{array}{l}22.78 \\
(5.28)\end{array}$ & 72.0 & 68.0 & 35.0 \\
3 & 109 & $\begin{array}{l}20.86 \\
(4.26)\end{array}$ & 76.1 & 63.3 & 33.9 \\
4 & 104 & $\begin{array}{l}19.11 \\
(2.61)\end{array}$ & 71.2 & 46.2 & 33.7 \\
& & $\begin{array}{l}\mathrm{F}(3,395)= \\
12.14 * *\end{array}$ & $\begin{array}{l}\chi^{2}(3, \mathrm{~N}= \\
398)=1.523\end{array}$ & $\begin{array}{l}\chi^{2}(3, \mathrm{~N}=396)= \\
18.61^{* *}\end{array}$ & $\begin{array}{l}\chi^{2}(3, \mathrm{~N}=398)= \\
.170\end{array}$ \\
\hline
\end{tabular}

${ }^{*} \mathrm{p}<.05,{ }^{* *} \mathrm{p}<.01$ 
A manipulation check for type of disability accommodated resulted in the exclusion of nine participants from data analysis. The manipulation check for type of disability measured the percentage of correct responses to the item that assessed the type of disability that the coworker mentioned in the business summary suffered from. Approximately $98 \%$ of participants provided a correct response to the manipulation check item, indicating that they recognized the type of accommodated. Data from a total of 399 participants were included in data analyses.

A 2 (procedural justice rules: six rules vs. zero rules) $\mathrm{x} 2$ (type of disability: severe back pain vs. major depressive disorder) between subjects design was used to investigate the proposed hypotheses. Participants that logged into the study via SonaSystems were placed in one of four conditions that reflected the four combinations that resulted from crossing two levels of procedural justice with two types of disabilities. These four conditions were: six procedural justice rules and severe back pain, six procedural justice rules and major depressive disorder, zero procedural justice rules and severe back pain, and zero procedural justice rules and major depressive disorder. Participants were asked to read a business summary and answer items regarding the fairness of several organizational policies and practices, including accommodations for employees with disabilities. Participants then completed a 56 item questionnaire that included measures of agreeableness, conscientiousness, emotional stability, self-esteem, and emotional intelligence. Additionally, participants completed an eight item questionnaire regarding demographics. It took participants approximately 30 minutes to complete this study. 


\section{Manipulations}

Procedural Justice. The presence of procedural justice was manipulated using a business summary that contained one accommodation scenario (Appendix 2). The business summary described aspects of a fictitious organization, such as type of business, company founder, employee characteristics, and early challenges. Each business summary contained one scenario that described an accommodation made for a coworker with a disability. In one condition, six procedural justice rules used to determine accommodations for employees with disabilities were described. The following is an excerpt from this condition:

FIG uses six guidelines when determining appropriate accommodations: 1) the same criteria is used for all employees when determining which employees who request accommodations actually receive them, 2) standard guidelines and criteria provided by the Americans with Disability Act are used to choose appropriate accommodations, 3 ) information from the employee requesting the accommodation as well as medical and legal consultants is taken into consideration, 4) the impact of accommodations on coworkers is taken into consideration, 5) accommodations reflect the moral and ethical standards of the organization, and 6) formal procedures are used to make corrections or adjustments to ineffective accommodations.

In another condition, there was no mention of the six procedural justice rules. The scenarios in both conditions were based on those used by Dineen, Noe, and Wang (2004) in a study examining the interaction between elements of procedural justice and individual differences for perceptions of fairness of a Web-based applicant screening process.

Type of Disability. The type of disability was manipulated using an accommodation scenario within the aforementioned business summary (Appendix 2). 
Each business summary contained one scenario that presented an example of an accommodation made for a coworker with a disability. Either a physical disability of psychological disorder was described in each scenario. An accommodation made for a coworker with severe back pain was discussed in the physical disability condition. The following is an excerpt from this condition:

FIG currently employs and accommodates five individuals with disabilities. including your coworker who suffers from a severe back condition, one of the most common disabilities. This condition makes it painful to sit and stand for long periods of time, lift heavy objects, and walk long distances. They are often fatigued at work due to back pain that affects their ability to sleep at night. Upon request, FIG used the six guidelines to provide your coworker with an accommodation that gives them an extra day off during the week and allows them to have extra breaks during their shift.

An accommodation made for a coworker with major depressive disorder was discussed in the psychological disorder condition. The following is an excerpt from this condition:

FIG currently employs and accommodates five individuals with disabilities, including your coworker who suffers from major depressive disorder, one of the most prevalent mood disorders. This condition causes them to show a lack of emotions, have delayed responses, and have thoughts of hopelessness. Your coworker takes antidepressant medication and attends weekly therapy sessions, but still has some difficulties performing their job duties. Upon request, FIG provided your coworker with an accommodation that transferred them to a position that provides a more flexible schedule, more supervision and support from management, and fewer time-sensitive tasks.

A list of 29 questions followed the business summary. The first five items were designed to assess participants' comprehension of the business summary and included one item that served as a manipulation check for the type of disability accommodated (Item 5) (Appendix 2). This item assessed participants' ability to recall the type of disability possessed by the coworker in the scenario. Participants were given four answer 
choices from which they indicated their response. This item asked "What type of disability did your coworker have?"

Within the next 24 items, six items served as a manipulation check for the presence of procedural justice (Items 9, 13, 20, 24, 27, \& 29) (Appendix 2). These items addressed the use of the six procedural justice rules within FIG. Participants rated their level of agreement using a Likert scale from 1 (Strongly Disagree) to 5 (Strongly Disagree). Sample items from this questionnaire include "The same criteria are used for all individuals when determining which FIG employees who request accommodations actually receive them." and "The impact of accommodations on coworkers is taken into consideration." The remaining 18 items included 4 items that assessed participants' fairness perceptions and 14 items that served as filler.

\section{Measures}

Fairness Perceptions. Fairness perceptions were measured using four items within the 29 item questionnaire that followed the business summary (Items 11, 18, 22, \& 26) (Appendix 2). The first set of two items assessed the fairness of the system used to determine appropriate accommodations. These items were adapted from ones used by Masterson, Lewis, Goldman, and Taylor (2000) in a study that examined employees' fairness perceptions of performance evaluation systems. The second set of two items addressed the fairness of the actual accommodation given to the coworker with a disability. Participants rated their level of agreement with each of the four statements using a Likert scale from 1 (Strongly Disagree) to 5 (Strongly Agree). Sample items from this questionnaire include "The accommodation system used by my organization is a fair one." and "I feel that FIG provided a fair accommodation for my coworker with severe 
back pain/major depressive disorder." The reliability of this scale as indexed by Cronbach's alpha was .80. This scale meets the requirement for good reliability (George $\&$ Mallery, 2008). An exploratory factor analysis showed that a single underlying factor explained $62.17 \%$ of the variance in this scale.

Agreeableness. Agreeableness was measured using a 10 item questionnaire from the International Personality Item Pool (IPIP), which is available online at http://ipip.ori.org (Appendix 3). This questionnaire corresponds to Costa and McCrae's (1992) NEO Personality Inventory (NEO-PI-R). It assessed individuals on statements that were positively and negatively related to agreeableness. Participants rated how accurately each item described themselves using a Likert scale from 1 (Very Inaccurate) to 5 (Very Accurate). Sample items from this questionnaire include "Have a good word for everyone." and "Have a sharp tongue." In this study, the reliability of this scale as indexed by Cronbach's alpha was .78. This scale meets the requirement for acceptable reliability. An exploratory factor analysis showed that two underlying factors explained $58.48 \%$ of the variance in this scale.

Conscientiousness. Conscientiousness was measured using a 10 item questionnaire from the IPIP, which is available online at http://ipip.ori.org (Appendix 3). This questionnaire corresponds to Costa and McCrae's (1992) NEO-PI-R. It assessed individuals on statements that were positively and negatively related to conscientiousness. Participants rated how accurately each item described themselves using a Likert scale from 1 (Very Inaccurate) to 5 (Very Accurate). Sample items from this questionnaire include "Am always prepared." and "Find it difficult to get down to work." In this study, the reliability of this scale as indexed by Cronbach's alpha is .86 . 
This scale meets the requirement for good reliability. An exploratory factor analysis showed that two underlying factors explained $57.09 \%$ of the variance in this scale.

Emotional Stability. Emotional stability was measured using a 10 item questionnaire from the IPIP, which is available online at http://ipip.ori.org (Appendix 3). This questionnaire corresponds to Costa and McCrae's (1992) NEO-PI-R. It assessed individuals on statements that were positively and negatively related to emotional stability. Participants rated how accurately each item described themselves using a Likert scale from 1 (Very Inaccurate) to 5 (Very Accurate). Sample items from this questionnaire include "Often feel blue." and "Rarely get irritated." In this study, the reliability of this scale as indexed by Cronbach's alpha was .86. This scale meets the requirement for good reliability. An exploratory factor analysis showed that two underlying factors explained $59.74 \%$ of the variance in this scale.

Self-esteem. Self-esteem was measured using a 10 item questionnaire from the IPIP, which is available at http://ipip.ori.org (Appendix 3). This questionnaire is based on Rosenberg's (1965) Personal Attribute Survey (PAS). It assessed an individual's current positive and negative feelings towards themselves. Participants rated how accurately each item described themselves using a Likert scale from 1 (Very Inaccurate) to 5 (Very Accurate). Sample items from this questionnaire include "Feel comfortable with myself." and "Am less capable than most people." In this study, the reliability of this scale as indexed by Cronbach's alpha was .83 . This scale meets the requirement for good reliability. An exploratory factor analysis showed that four underlying factors explained $63.60 \%$ of the variance in this scale. 
Emotional Intelligence. Emotional intelligence was measured using the Wong and Law Emotional Intelligence Scale (WLEIS) developed by Wong and Law (2002) (Appendix 3). This 16 item questionnaire assessed individuals on self-emotions appraisal, use of emotion, regulation of emotion, and others' emotion appraisal. Participants rated how accurately each item described themselves using a Likert scale from 1 (Totally Disagree) to 7 (Totally Agree). Sample items from this questionnaire include "I have a good understanding of my own emotions." and "I am quite capable of controlling my own emotions." In this study, the reliability of this scale as indexed by Cronbach's alpha was .88 . This scale meets the requirement for good reliability. An exploratory factor analysis showed that four underlying factors explained $69.55 \%$ of the variance in this scale.

Demographics. Participants completed an eight item questionnaire that assessed individual characteristics, such as gender, age, grade classification, race, ethnicity, employment status, and interaction with persons with disabilities (Appendix 4).

\section{Pilot Study}

Prior to the beginning of the main study, a small pilot study was conducted. Fiftyfive undergraduate students were randomly assigned to conditions. Participants completed a paper version of the business summary and responded to the 29 item questionnaire that contained the manipulation checks and dependent variable (Appendix 2), the 56 item personality questionnaire (Appendix 3), and the eight item demographics questionnaire (Appendix 4). This pilot study was done to verify that the accommodation scenarios and corresponding questions were easy to understand and was eliciting appropriate responses. Analyses of the manipulation check item for type of disability 
accommodated showed that all 28 individuals presented with the physical disability and all 27 individuals presented with the psychological disorder correctly responded to this item. As a result of these findings, the main online study was conducted according to the methods previously described. The following chapter presents the results of the main study. 


\section{Chapter IV: Results}

Table 2 presents the correlations among the study variables for the total sample. Appendix 1 provides the correlations among the study variables for each wave.

Table 2

Intercorrelations Between Individual Characteristics and Fairness Perceptions

\begin{tabular}{|c|c|c|c|c|c|c|c|c|c|c|c|c|c|c|c|}
\hline & $\mathrm{M}$ & $\mathrm{SD}$ & 1 & 2 & 3 & 4 & 5 & 6 & 7 & 8 & 9 & 10 & 11 & 12 & 13 \\
\hline 1. PJ Rules ${ }^{a}$ & 0.52 & .50 & - & & & & & & & & & & & & \\
\hline 2. Disability Type ${ }^{b}$ & 0.50 & .50 & -.02 & - & & & & & & & & & & & \\
\hline 3. Fairness Rating & 4.20 & .58 & $-.10^{*}$ & -.05 & $(.80)$ & & & & & & & & & & \\
\hline 4. Agreeableness & 3.88 & .50 & .05 & -.09 & $.19^{* *}$ & $(.78)$ & & & & & & & & & \\
\hline 5. Conscientiousness & 3.93 & .59 & .001 & $-.12 *$ & $.18^{* *}$ & $.34 * *$ & $(.86)$ & & & & & & & & \\
\hline 6. Emotional Stability & 2.23 & .66 & .03 & .03 & $-.15 * *$ & $-.37 * *$ & $-.44 * *$ & $(.86)$ & & & & & & & \\
\hline 7. Self-esteem & 4.10 & .53 & -.06 & -.08 & $.17 * *$ & $.27 * *$ & $.57 * *$ & $-.76^{* *}$ & $(.83)$ & & & & & & \\
\hline $\begin{array}{l}\text { 8. Emotional } \\
\text { Intelligence }\end{array}$ & 5.63 & .71 & .02 & -.04 & $.16^{* *}$ & $.41 * *$ & $.57^{* *}$ & $-.62 * *$ & $.64 * *$ & $(.88)$ & & & & & \\
\hline 9. Gender ${ }^{\mathrm{C}}$ & 0.73 & .44 & -.02 & -.02 & .06 & $.15^{* *}$ & $.12 *$ & .03 & .001 & .03 & - & & & & \\
\hline 10. Age & 21.19 & $\begin{array}{c}4.8 \\
6\end{array}$ & $-.26 * *$ & -.05 & -.03 & .01 & .03 & -.07 & .09 & .06 & -.06 & - & & & \\
\hline 11. Hispanic Origin ${ }^{d}$ & 0.25 & .43 & .01 & .06 & -.003 & -.04 & -.06 & -.03 & -.001 & .01 & .01 & .10 & - & & \\
\hline 12. Employment ${ }^{\mathrm{e}}$ & 0.37 & .48 & $.17 * *$ & $.12 *$ & .08 & -.03 & -.05 & -.02 & -.03 & .03 & -.06 & $-.17 * *$ & .04 & - & \\
\hline 13. Disability ${ }^{f}$ & 0.66 & .47 & .02 & -.002 & .04 & .05 & -.03 & -.07 & .02 & .04 & -.01 & -.03 & .06 & -.03 & - \\
\hline
\end{tabular}

${ }^{\mathrm{a}}$ Dummy coded: $0=$ six procedural justice rules, $1=$ zero procedural justice rules; ${ }^{\mathrm{b}}$ Dummy coded: $0=$ physical disability, $1=$ psychological disorder; ${ }^{\mathrm{c}}$ Dummy coded: $0=$ male, $1=$ female; ${ }^{\mathrm{d}}$ Dummy coded: $0=$ Hispanic, $1=$ non-Hispanic; ${ }^{\mathrm{e}}$ Dummy coded: $0=$ employed $1=$ unemployed; ${ }^{\mathrm{f}}$ Dummy coded: $0=$ yes, $1=$ no.

${ }^{*} \mathrm{p}<.05,{ }^{* *} \mathrm{p}<.01$. 
Manipulation Checks. A manipulation check for procedural justice was conducted to verify that participants identified the material that they were exposed to as expected. An independent groups $\mathrm{t}$ test tested this manipulation by comparing the mean rating on the manipulation check items for the six procedural justice rules condition $(M=4.11, S D$ $=0.53$ ) with the mean rating on the manipulation check items for the zero procedural justice rules condition $(\mathrm{M}=3.82, \mathrm{SD}=0.53)$. This test was found to be statistically significant at an alpha level of $.05, \mathrm{t}(397)=5.436, \mathrm{p}<.01$, indicating that participants had higher levels of agreement with the manipulation check items in the six procedural justice rules condition than in the zero procedural justice rules condition. The strength of the relationship between the presence of procedural justice and the responses on the manipulation check items as indexed by the d-value was .55 . The $95 \%$ confidence interval for the mean difference was 0.53 to 0.57 . It is interesting to note that the mean rating on the manipulation check items in the condition without procedural justice rules was high. This finding suggests that participants and perhaps the general population are trustworthy of organizations and generally view organizations in a positive fashion. Although mean ratings on the manipulation check items were high for both types of conditions, the difference in ratings was statistically significant. As stated in the description of study participants, a manipulation check for type of disability accommodated was also conducted. Nine participants were excluded from data analysis due to their incorrect response to this item.

Hypotheses Testing. Hypothesis 1 predicted that mean fairness perceptions of accommodations made using the six procedural justice rules would be higher than mean fairness perceptions of accommodations made without using the six procedural justice 
rules. An independent groups $t$ test tested this hypothesis by comparing the mean fairness rating for the six procedural justice rules condition $(\mathrm{M}=4.26, \mathrm{SD}=0.57)$ with the mean fairness rating for the zero procedural justice rules condition $(M=4.14, S D=0.59)$. This test was found to be statistically significant at an alpha level of $.05, \mathrm{t}(397)=2.07, \mathrm{p}<.05$ (one-tailed), indicating that accommodations made for employees with disabilities were viewed as fairer when they were determined using the six procedural justice rules than when procedural justice rules were not used. The strength of the relationship between the presence of procedural justice and fairness perceptions as indexed by the d-value was .21 . The $95 \%$ confidence interval for the mean difference was .19 to .23 .

Hypothesis 2 predicted that mean fairness perceptions of accommodations made for individuals with physical disabilities would be higher than mean fairness perceptions of accommodations made for individuals with mood disorders. An independent groups $\mathrm{t}$ test tested this hypothesis by comparing the mean fairness rating for the physical disability condition, severe back pain $(\mathrm{M}=4.22, \mathrm{SD}=0.60)$ with the mean fairness rating for the psychological disorder condition, major depressive disorder $(\mathrm{M}=4.17, \mathrm{SD}=$ 0.57). This test was not found to be statistically significant at an alpha level of .05, t(397) $=.913, \mathrm{p}>.18$ (one-tailed), indicating that accommodations made for individuals with physical disabilities and accommodations made for individuals with psychological disorders were viewed as equally fair. Table 3 presents the results of the comparison of mean fairness ratings for presence of procedural justice and type of disability. 
Table 3

Mean Fairness Ratings for Each Condition

\begin{tabular}{|c|c|c|c|}
\hline Condition & $\mathrm{N}$ & $\begin{array}{l}\text { Mean Fairness } \\
\text { Rating }\end{array}$ & Standard Deviation \\
\hline $\begin{array}{l}\text { Procedural Justice- Physical } \\
\text { Disability }\end{array}$ & 94 & 4.29 & .61 \\
\hline $\begin{array}{l}\text { Procedural Justice- } \\
\text { Psychological Disorder }\end{array}$ & 96 & 4.23 & .54 \\
\hline $\begin{array}{l}\text { No Procedural Justice- } \\
\text { Physical Disability }\end{array}$ & 107 & 4.16 & .58 \\
\hline $\begin{array}{l}\text { No Procedural Justice- } \\
\text { Psychological Disorder }\end{array}$ & 102 & 4.12 & .60 \\
\hline
\end{tabular}

Due to the significant difference in the percentage of employed participants in Wave 4 as compared to Waves 1-3, Hypotheses 1 and 2 were also tested using an analysis of covariance (ANCOVA). For Hypothesis 1, the mean fairness rating of accommodations made with the six procedural justice was compared to the mean fairness rating of accommodations made without the procedural justice rules while using employment as a covariate. This test was found to be statistically significant at an alpha level of $.05, F(1,393)=5.38, p<.05$. Accommodations made using the six procedural justice rules $(M=4.26, S D=0.58)$ received significantly higher fairness ratings than accommodations made without using procedural justice rules $(\mathrm{M}=4.14, \mathrm{SD}=0.59)$. This is similar to the analysis without the covariate. The $F$ value for the covariate was $F(1$, $393)=3.921, p<.05$. For Hypothesis 2 , the mean fairness rating of accommodations made for severe back pain was compared with the mean fairness rating of accommodations made for major depressive disorder while using employment as a covariate. Similar to the analysis without the covariate, the test was not found to be statistically significant at an alpha level of $.05, F(1,393)=1.120, p>.10$. The $F$ value for the covariate was $F(1,393)=2.926, p>.10$. Accommodations made for severe back 
pain $(M=4.22, S D=0.60)$ did not receive significantly higher fairness ratings than accommodations made for major depressive disorder $(\mathrm{M}=4.17, \mathrm{SD}=0.57)$.

Hypothesis 3 predicted that the interaction between the presence of procedural justice rules and the type of disability would influence the mean fairness perceptions of accommodations made for coworkers with disabilities. Fairness perceptions were subjected to a two-way analysis of variance (ANOVA) having two levels of procedural justice (six rules and zero rules) and two levels of disability type (severe back pain and major depressive disorder). This test was not found to be statistically significant at an alpha level of $.05, F(1,395)=0.01, p>.10$, indicating that the interaction between procedural justice and disability type did not have a significant influence on individuals' overall fairness ratings for accommodations made for individuals with disabilities.

Hypothesis 4 predicted that agreeableness would moderate the relationship between procedural justice and perceptions of fairness, such that individuals low in agreeableness would give greater weight to the presence of procedural justice than individuals high in agreeableness. A hierarchical regression was used to test this hypothesis. Due to the statistically significant difference in employment among conditions, employment was included in these analyses as a covariate. Procedural justice (six rules or zero rules) and employment (yes or no) were dummy coded using the values 0 and 1. Fairness perceptions were then regressed on the presence of procedural justice, employment, agreeableness, and the interaction term for procedural justice and agreeableness. This analysis was not found to be statistically significant at an alpha level of $.05, F(4,395)=6.46, \Delta R^{2}=.003, p>.10$, indicating that an individual's level of 
agreeableness does not affect the relationship between the presence of procedural justice and fairness perceptions of accommodations made for employees with disabilities. Table 4 presents the results of the hierarchical regression used to test the moderating effects of agreeableness.

Table 4

Hierarchical Regression Analyses for Agreeableness Predicting Fairness

Perceptions

\begin{tabular}{lc}
\hline \multicolumn{1}{c}{ Variable } & $\beta$ \\
\hline Step 1 & \\
Procedural Justice $(0 / 1)$ & $-.12^{*}$ \\
Employment $(0 / 1)$ & $.10^{*}$ \\
$\mathrm{R}^{2}$ & $.020^{* *}$ \\
Step 2 & \\
Procedural Justice $(0 / 1)$ & $-.13^{* *}$ \\
Employment $(0 / 1)$ & $.11^{*}$ \\
Agreeableness & $.20^{* *}$ \\
$\mathrm{R}^{2}$ & $.059^{* *}$ \\
$\Delta \mathrm{R}^{2}$ & $.039^{* *}$ \\
Step 3 & \\
Procedural Justice $(0 / 1)$ & $-.13^{* *}$ \\
Employment $(0 / 1)$ & $.11^{*}$ \\
Agreeableness & $.26^{* *}$ \\
PJ $\mathrm{x}$ Agreeableness & -.09 \\
$\mathrm{R}^{2}$ & $.062^{* *}$ \\
$\Delta \mathrm{R}^{2}$ & .003 \\
\hline${ }^{*} \mathrm{p}<.05,{ }^{* *} \mathrm{p}<.01$. &
\end{tabular}

Hypothesis 5 predicted that conscientiousness would moderate the relationship between procedural justice and perceptions of fairness, such that individuals high in conscientiousness would give greater weight to the presence of presence of procedural justice than individuals low in conscientiousness. A hierarchical regression was used to test this hypothesis. Due to the statistically significant difference in employment among conditions, employment was included in these analyses as a covariate. Procedural justice (six rules or zero rules) and employment (yes or no) were dummy coded using the values 
0 and 1. Fairness perceptions were then regressed on the presence of procedural justice, employment, conscientiousness, and the interaction term for procedural justice and conscientiousness. This analysis was found to be statistically significant at an alpha level of $.05, \mathrm{~F}(4,395)=6.55, \Delta \mathrm{R}^{2}=.011, \mathrm{p}<.05$, indicating that an individual's level of conscientiousness affects the relationship between the presence of procedural justice and fairness perceptions of accommodations made for employees with disabilities. Table 5 presents the results of the hierarchical regression used to test the moderating effects of conscientiousness. As presented in Figure 1, individuals high in conscientiousness gave greater weight to the presence of procedural justice than individuals low in conscientiousness.

Table 5

Hierarchical Regression Analyses for Conscientiousness Predicting Fairness Perceptions

\begin{tabular}{lc}
\hline \multicolumn{1}{c}{ Variable } & $\beta$ \\
\hline Step 1 & \\
Procedural Justice $(0 / 1)$ & $-.12^{*}$ \\
Employment $(0 / 1)$ & $.10^{*}$ \\
$\mathrm{R}^{2}$ & $.020^{*}$ \\
Step 2 & \\
Procedural Justice $(0 / 1)$ & $-.12^{*}$ \\
Employment $(0 / 1)$ & $.11^{*}$ \\
Conscientiousness & $.18^{* *}$ \\
$\mathrm{R}^{2}$ & $.052^{*}$ \\
$\Delta \mathrm{R}^{2}$ & $.032^{* *}$ \\
Step 3 & \\
Procedural Justice $(0 / 1)$ & $-.12^{*}$ \\
Employment $(0 / 1)$ & $.10^{*}$ \\
Conscientiousness & $.28^{* *}$ \\
$\mathrm{PJ}_{\mathrm{x}}$ Conscientiousness & $-.15^{*}$ \\
$\mathrm{R}^{2}$ & $.063^{* *}$ \\
$\Delta \mathrm{R}^{2}$ & $.011^{*}$ \\
\hline$* \mathrm{p}<.05, * * \mathrm{p}<.01$. &
\end{tabular}


Figure 1

Presentation of Hierarchical Regression Analyses for Conscientiousness Predicting Fairness Perceptions

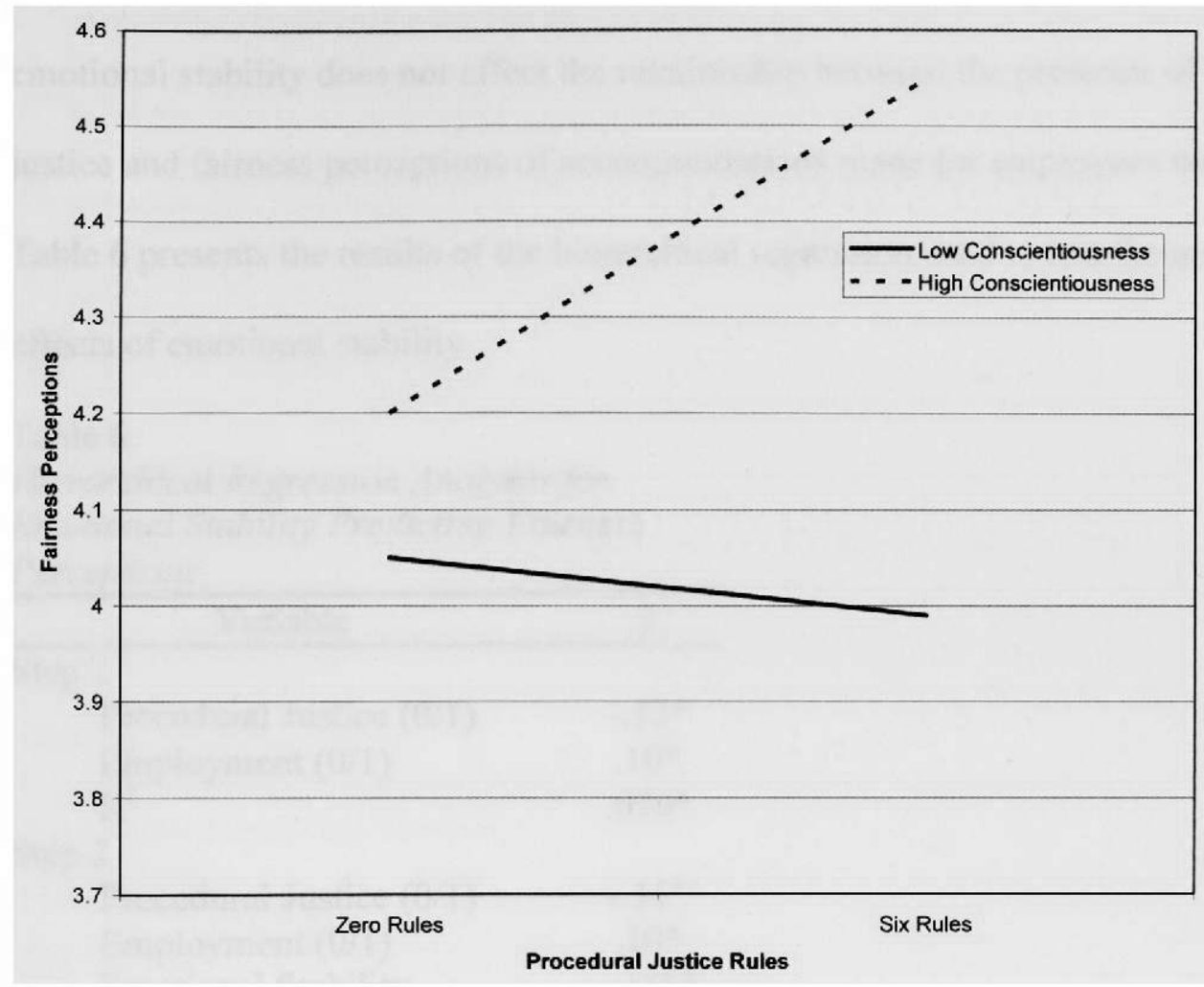

Hypothesis 6 predicted that emotional stability would moderate the relationship between procedural justice and perceptions of fairness, such that individuals low in emotional stability would give greater weight to the presence of procedural justice than individuals high in emotional stability. A hierarchical regression was used to test this hypothesis. Due to the statistically significant difference in employment among conditions, employment was included in these analyses as a covariate. Procedural justice (six rules or zero rules) and employment (yes or no) were dummy coded using the values 0 and 1. Fairness perceptions were then regressed on the presence of procedural justice, employment, emotional stability, and the interaction term for procedural justice and 
emotional stability. This analysis was not found to be statistically significant at an alpha level of $.05, F(4,395)=4.33, \Delta \mathrm{R}^{2}=.001, \mathrm{p}>.10$, indicating that an individual's level of emotional stability does not affect the relationship between the presence of procedural justice and fairness perceptions of accommodations made for employees with disabilities. Table 6 presents the results of the hierarchical regression used to test the moderating effects of emotional stability.

Table 6

Hierarchical Regression Analyses for

Emotional Stability Predicting Fairness

Perceptions

\begin{tabular}{ll}
\hline \multicolumn{1}{c}{ Variable } & $\beta$ \\
\hline Step 1 & \\
Procedural Justice $(0 / 1)$ & $-.12^{*}$ \\
Employment $(0 / 1)$ & $.10^{*}$ \\
$\mathrm{R}^{2}$ & $.020^{*}$
\end{tabular}

Step 2

Procedural Justice (0/1) $\quad-.11^{*}$

Employment (0/1) $\quad .10^{*}$

Emotional Stability $\quad-.15^{* *}$

$\mathrm{R}^{2} \quad .041^{* *}$

$\Delta \mathrm{R}^{2} \quad .021^{* *}$

Step 3

Procedural Justice (0/1) $\quad-.11^{*}$

Employment (0/1) $\quad .10$

Emotional Stability $\quad-.18^{*}$

PJ x Emotional Stability $\quad .05$

$\mathrm{R}^{2} \quad .042^{* *}$

$\Delta \mathrm{R}^{2} \quad .001$

${ }^{*} \mathrm{p}<.05,{ }^{* *} \mathrm{p}<.01$.

Hypothesis 7 predicted that self-esteem would moderate the relationship between procedural justice and perceptions of fairness, such that individuals with high self-esteem would give greater weight to the presence of procedural justice than individuals with low self-esteem. A hierarchical regression was used to test this hypothesis. Due to the 
statistically significant difference in employment among conditions, employment was included in these analyses as a covariate. Procedural justice (six rules or zero rules) and employment (yes or no) were dummy coded using the values 0 and 1 . Fairness

perceptions were then regressed on the presence of procedural justice, employment, selfesteem, and the interaction term for procedural justice and self-esteem. This analysis was not found to be statistically significant at an alpha level of $.05, F(4,395)=5.08, \Delta \mathrm{R}^{2}=$ $.004, p>.10$, indicating that an individual's level of self-esteem does not affect the relationship between the presence of procedural justice and fairness perceptions of accommodations made for employees with disabilities. Table 7 presents the results of the hierarchical regression used to test the moderating effects of self-esteem.

\section{Table 7}

Hierarchical Regression Analyses for

Self-esteem Predicting Fairness

Perceptions

\begin{tabular}{cc}
\hline \multicolumn{1}{c}{ Variable } & $\beta$ \\
\hline Step 1 & \\
Procedural Justice $(0 / 1)$ & $-.12^{*}$ \\
Employment $(0 / 1)$ & $.10^{*}$ \\
$\mathrm{R}^{2}$ & $.020^{*}$
\end{tabular}

Step 2

Procedural Justice $(0 / 1) \quad-.11^{*}$

Employment (0/1) .10*

Self-esteem $\quad .16^{* *}$

$\mathrm{R}^{2} \quad .045^{* *}$

$\Delta \mathrm{R}^{2} \quad .026^{* *}$

Step 3

Procedural Justice (0/1) $\quad-.11^{*}$

Employment (0/1) .10*

Self-esteem .23**

PJ x Self-esteem $\quad-.09$

$\mathrm{R}^{2} \quad .049^{* *}$

\begin{tabular}{ll}
$\Delta \mathrm{R}^{2}$ & .004 \\
\hline
\end{tabular}

${ }^{*} \mathrm{p}<.05,{ }^{* *} \mathrm{p}<.01$.

Hypothesis 8 predicted that emotional intelligence would moderate the 
relationship between procedural justice and perceptions of fairness, such that individuals low in emotional intelligence would give greater weight to the presence of procedural justice than individual high in emotional intelligence. A hierarchical regression was used to test this hypothesis. Due to the statistically significant difference in employment among conditions, employment was included in these analyses as a covariate. Procedural justice (six rules or zero rules) and employment (yes or no) were dummy coded using the values 0 and 1 . Fairness perceptions were then regressed on the presence of procedural justice, employment, emotional intelligence, and the interaction term for procedural justice and emotional intelligence. This analysis was not found to be statistically significant at an alpha level of $.05, F(4,395)=4.67, \Delta R^{2}=.002, p>.10$, indicating that an individual's level of emotional intelligence does not affect the relationship between the presence of procedural justice and fairness perceptions of accommodations made for employees with disabilities. Table 8 presents the results of the hierarchical regression used to test the moderating effects of emotional intelligence. 
Table 8

Hierarchical Regression Analyses for

Emotional Intelligence Predicting Fairness

Perceptions

\begin{tabular}{lc}
\hline \multicolumn{1}{c}{ Variable } & $\beta$ \\
\hline Step 1 & $-.12^{*}$ \\
Procedural Justice $(0 / 1)$ & $.10^{*}$ \\
Employment $(0 / 1)$ & .020 \\
$\mathrm{R}^{2}$ & \\
Step 2 & $-.12^{*}$ \\
Procedural Justice $(0 / 1)$ & .10 \\
Employment $(0 / 1)$ & $.15^{* *}$ \\
Emotional Intelligence & $.044^{* *}$ \\
$\mathrm{R}^{2}$ & $.024^{* *}$ \\
$\Delta \mathrm{R}^{2}$ & \\
Step 3 & $-.12^{*}$ \\
Procedural Justice $(0 / 1)$ & .10 \\
Employment $(0 / 1)$ & $.20^{* *}$ \\
Emotional Intelligence & -.07 \\
$\mathrm{PJ}$ x Emotional Intelligence & $.046^{* *}$ \\
$\mathrm{R}^{2}$ & .002 \\
$\Delta \mathrm{R}^{2}$ & \\
\hline
\end{tabular}

${ }^{*} \mathrm{p}<.05,{ }^{* *} \mathrm{p}<.01$. 


\section{Chapter V: Discussion}

Employees with disabilities face many challenges throughout their participation in the different phases of employment. When compared to their non-disabled counterparts, individuals with disabilities included in the United States workforce are more likely to be unemployed, overlooked for qualified positions, and the recipients of lower pay (McFarlin et al., 1991; Stone-Romereo et al., 2006). Once persons with disabilities are employed, they often have trouble integrating into their work group. This is frequently due to the difficulty they have developing close relationships with their coworkers. One commonly suggested reason for this challenge in fostering relationships between disabled and non-disabled coworkers is the possible negative perception that non-disabled workers have of accommodations made for employees with disabilities. These perceptions are important because at times, non-disabled employees are called upon to assist in the accommodation of their disabled coworkers (Colella, 2001). The present study was conducted in order to gain a better understanding of the factors that influence coworkers' fairness perceptions of accommodations made for employees with disabilities. The theory of procedural justice provided a framework for the development of this study. Hypotheses for this study centered on the presence of procedural justice and the type of disability accommodated as main determinants of fairness perceptions. Additionally, the type of disability accommodated and five individual characteristics (agreeableness, conscientiousness, emotional stability, self-esteem, and emotional intelligence) were predicted to moderate the relationship between procedural justice and fairness perceptions. 
Approximately 400 university students read one of four accommodation scenarios and provided fairness ratings in order to test eight hypotheses. Results from this study offer insight into the important role that procedural justice plays in the formation of fairness judgments for accommodations provided to employees with disabilities. Also, greater information was provided regarding the disability-related and person-related characteristics that affect the strength of the relationship between procedural justice and fairness perceptions.

The results of this study support the hypothesis that accommodations made using the six procedural justice rules received significantly higher fairness ratings than accommodations made without the procedural justice rules. The type of disability that was accommodated did not affect individuals' fairness perceptions of accommodations made. Conscientiousness was found to moderate the relationship between the presence of procedural justice and fairness perceptions of accommodations for workers with disabilities, but the type of disability accommodated, agreeableness, emotional stability, self-esteem, and emotional intelligence were not found to have the same impact. The following section discusses the results for the hypothesized direct impact of procedural justice and type of disability on fairness perceptions of accommodations made for employees with disabilities. Investigation of Main Effects

As previously stated, participants viewed accommodations made using the six procedural justice rules as fairer than accommodations made without the procedural justice rules. Although the impact of procedural justice on fairness perceptions was found to be statistically significant, it may also be the case that this effect was underestimated. 
I nis is suggested due to the statistically significant difference in the age and employment status of participants in the fourth condition, zero procedural justice rules and major depressive disorder. The majority of individuals in this condition were young and unemployed. It seems that due to the nature of the accommodation described in this condition, it would have been especially important for participants to have work experience. Work experience would provide them with a more realistic view of how policies are enacted within organizations and the ability to understand the type of impact that accommodating employees with disabilities could have on non-disabled workers. Perhaps if this condition had been comprised of a larger number of older and employed individuals, lower fairness ratings for this condition and a more significant effect of the presence of procedural justice rules on fairness perceptions may have been found. Associated with the findings for the effect of procedural justice on fairness perceptions, it is interesting to consider how the results of this study would have differed if two additional conditions had been added. An unfair process for determining accommodations for either severe back pain or major depressive disorder would be described in these conditions. Based on the current study's results, it would be expected that accommodations made using the six procedural justice rules would receive the highest fairness ratings and the accommodations made with unfair processes would receive the lowest fairness ratings. Although the use of specific guidelines to determine accommodations would not be mentioned in the zero procedural justice rules conditions, the findings from the current study suggest that participants would assume that fair procedures were used to determine accommodations. This assumption would result in 
higher fairness ratings for accommodations made without procedural justice than those made with unfair processes.

Even though accommodations made for physical disabilities were expected be viewed as fairer than accommodations made for psychological disorders independent of the presence of procedural justice, both types of accommodations received high average fairness ratings. These results are somewhat in contrast to those of Goldstein and Blackman (1975) who found that individuals with psychological and sensory disorders were viewed less favorably when compared to individuals with physical disabilities; similar results were not found for the perceptions of accommodations made for both classes of disabilities. Despite the lack of a clear indication that persons with physical disabilities and persons with a psychological disorders are looked at as equally favorable, the absence of a significant difference in fairness ratings suggests that accommodations for both groups are viewed as justified. These results imply that people are generally receptive to employees with disabilities receiving accommodations, and perhaps these accommodations are viewed as necessary assistance rather than unfair advantages. Furthermore, these results seem to reflect a shift in the public's perception and understanding of the nature and accommodation of various types of disabilities.

However, similar to the findings for the impact of the presence of procedural justice on fairness perceptions, the results for type of disability of accommodated should be tempered by the nature of the sample used. Participants in this study were all psychology majors, who due to their knowledge and interest in psychology may have had a different perspective on depression that made it easier for them to recognize it as a real disorder. This increased understanding of psychological disorders, may have contributed 
to the underestimation of the influence of the type of disability on fairness ratings for accommodations made for employees. Perhaps if the sample had been comprised of a diverse group of majors, mean fairness ratings for accommodations made for major depressive disorder may have been lower which may have resulted in a significant impact of type of disability on fairness ratings.

The following section explores the results for the hypothesized moderators of the relationship between procedural justice and fairness perceptions of accommodations made for individuals with disabilities. Additionally, alternative explanations for such findings are proposed.

\section{Alternative Explanations}

Due to the lack of significant results for the majority of predicted individual characteristics as moderators for the relationship between procedural justice and fairness perceptions for accommodations made for employees with disabilities, five alternative explanations were developed. The first alternative explanation focuses on the role that employment status may have played in participants' fairness perceptions of the accommodation presented in the accommodation scenario. One important element of many accommodations is that they require the help or participation of non-disabled employees. This assistance may include, but is not limited to, swapping schedules, taking on additional tasks, switching tasks, and/or making adjustments to the work environment. It is thought that due to their work experience and exposure to office politics, employed participants may have greater insight into and understanding of the possible personal changes they would have to make if a disabled coworker received an accommodation. 
Also, employed participants may have actually experienced the accommodation of a coworker's disability. This insight may have affected their fairness ratings of the accommodation presented in the scenario. To test this explanation, a hierarchical regression that only included employed participants was calculated for each individual characteristic. Age was the only variable that correlated with outcome variables and therefore was used as a covariate in these analyses. As the results presented in Appendix 5 suggest, employment did not affect fairness ratings such that individual characteristics were not found to moderate the relationship between the presence of procedural justice and fairness perceptions of accommodations made for employees with disabilities.

The second alternative explanation is related to the influence of individual characteristics on the relationship between procedural justice and fairness perceptions of outcomes that directly and indirectly affect an individual. Although agreeableness, emotional stability, and self-esteem have been found to act as moderators for the relationship between distributive justice, interactional justice, or procedural justice and employee perceptions of or reactions to new organizational systems and policies, such results were found in studies that examined decisions that had a direct impact on the individual making the fairness judgment (Skarlicki et al., 1999; Zweig \& Webster, 2003; Brockner et al., 1998). Despite the fact that some accommodations made for employees with disabilities directly affect non-disabled coworkers, those that do not may be less likely to receive the same level of scrutiny and have the same amount of personal investment from non-disabled coworkers. This is especially applicable to the accommodations described in this study. Neither accommodation required any involvement from employees without disabilities. Perhaps if the accommodations 
presented in this study required some type of involvement or assistance from nondisabled coworkers, these individual characteristics would have had a greater influence on their fairness perceptions.

Related to this point is the idea that the likelihood of detecting the influence of individual characteristics on the procedural justice-fairness perceptions link can be affected by the extent to which an individual views an organization's policies and procedures as verifying the way that they view themselves. This is especially relevant for the individual characteristic, self-esteem. Wiesenfeld, Swann, Brockner, and Bartell (2007) found that self-esteem moderates the relationship between procedural justice and organizational commitment. There was a strong present relationship between procedural justice and organizational commitment for individuals with high self-esteem, but for individuals low in self-esteem the relationship between the variables of interest was absent. These results suggest that when an organization uses policies and procedures that are congruent with the employee's self-perception, that employee will be more satisfied with the outcome. Perhaps similar results were not found in the current study because the accommodations presented did not require any involvement from participants, and as a consequence the presence or absence of procedural justice rules was not interpreted as a reflection of how the organization viewed them.

The third alternative explanation focuses on the separation of interaction effects and main effects. Although results from this study suggest that most individual characteristics do not affect fairness perceptions through their interaction with the presence of procedural justice, this does not mean that they cannot influence fairness perceptions. Perhaps individual characteristics have a direct impact on fairness 
perceptions. Results from previous studies support this line of thinking. Bernerth, Field, Giles, and Cole (2006) found that agreeableness, openness to experience, and test-taking self-efficacy were all positively related to perceptions of procedural justice within a selection context. Furthermore, Avery (2003) found that extraversion and self-efficacy were significant predictors of the value that an individual places on being able to share their opinion or provide input during the decision-making process. Based on these results, the main effect of individual characteristics on fairness perceptions of accommodations made for employees with disabilities was examined. As presented in Table 2, the correlations between each individual characteristic and fairness perceptions were statistically significant at an alpha level of .01 indicating that each individual characteristic is directly related to fairness perceptions. Agreeableness, conscientiousness, self-esteem, and emotional intelligence were found to be positively related to fairness perceptions, while emotional stability was found to be negatively related to fairness perceptions. The results of the hierarchical regressions presented in Tables 4-8, reinforce the assertion that each individual characteristic has a direct influence on fairness perceptions. Agreeableness, conscientiousness, emotional stability, self-esteem, and emotional intelligence were all found to have statistically significant main effects. Results from both types of analyses suggest that although individual characteristics do not moderate the relationship between procedural justice and fairness perceptions, they do directly affect fairness perceptions.

The fourth alternative explanation centered on the effects of the underlying factors of variables on the relationship between procedural justice and coworkers' fairness perceptions of accommodations made for employees with disabilities. Perhaps 
each factor rather than the combination of factors cause interactive effects. This is particularly applicable to the individual characteristic, emotional intelligence.

Emotionally intelligent individuals are characterized as being apt at managing their emotions, delaying gratification, reading and handling others' emotions, and effectively managing conflict (Myers, 2002). As suggested in the description of an individual high in emotional intelligence, there are four underlying factors of this variable: self-emotions appraisal, others-emotions appraisal, regulation of emotion, and use of emotion (Davies, Stankov, \& Roberts, 1998; Law, Wong, \& Song, 2004). Self-emotions appraisal refers to a person's natural aptitude for understanding and expressing their own emotions. Others-emotions appraisal refers to the capacity of an individual to recognize and comprehend the emotions of others. Regulation of emotion refers to an individual's capability to control their emotions, which results in faster recovery when exposed to psychological stressors. Use of emotion to refers to the ability of an individual to use their emotions to perform productive tasks and improve performance. Based on the description of each factor, it is suggested that certain factors such as others-emotions appraisal and regulation of emotion, may be more likely than others to moderate the relationship between procedural justice and fairness perceptions of accommodations made for employees with disabilities. A hierarchical regression was performed for each emotional intelligence factor to test this prediction. As presented in Appendix 6, the four factors of emotional intelligence did not moderate the relationship between procedural justice and fairness perceptions.

An additional explanation may exist for the lack of a moderating affect of emotional intelligence on the relationship between the presence of procedural justice and 
fairness perceptions of accommodations made for employees with disabilities. Significant gender differences in levels of emotional intelligence may have weakened the chances of seeing the moderating affect of emotional intelligence. Although there have been mixed results, several studies have found gender difference in levels of emotional intelligence. In a study that examined men and women's differences in self-estimated and measured emotional intelligence, women were found to have significantly higher levels of measured emotional intelligence than men (Petrides \& Furnham, 2000). Additionally, within an organizational context, female managers were found to have higher levels of emotional intelligence than male managers (Mandell \& Pherwani, 2003). Based on these findings a $t$ test was performed to determine if there was a significant difference in mean emotional intelligence scores between male and female participants. These analyses were done for each condition as well as across conditions. As presented in Appendix 7, a significant gender difference in emotional intelligence was not found.

The fifth alternative explanation focuses on the influence of individual levels of conscientiousness on the moderating effects of individual characteristics. Although, the majority of individual characteristics (agreeableness, emotional stability, self-esteem, and emotional intelligence) were not found to influence the relationship between procedural justice and fairness perceptions, analyses that factor in participants' level of conscientiousness might result in alternate findings. Conscientiousness describes the amount if self-discipline and achievement-striving that an individual possesses (Barrick \& Mount, 1991). Due to the nature of this study, it is suggested that conscientiousness may have played an important role in individuals' quality of participation and subsequent study results. Conscientious participants may have paid closer attention when completing 
all measures than individuals low in conscientious, which would make it more likely that moderating effects would be detected for conscientious individuals. A hierarchical regression was conducted in order to test the hypothesis that there was a three-way interaction between each individual characteristic, conscientiousness, and the presence of procedural justice. As presented in Appendix 8, conscientiousness was found to affect the moderating influence of emotional stability. Appendix 9 provides a graphical presentation of these results.

Due to the presence of a three-way interaction, additional analyses were performed in order to determine which level of conscientiousness had the greatest influence on the likelihood that moderating effects would be detected. Participants were organized according to their scores on the conscientiousness measure and divided into three groups of equal size (high score, moderate score, and low score). The top one hundred individuals from the high score and low score group were then determined. Only these individuals were used in these analyses. Separate hierarchical regressions were run for each group to assess the influence of agreeableness, emotional stability, self-esteem, and emotional intelligence on the relationship between procedural justice and fairness perceptions. As presented in Appendices 10 and 11, individual characteristics were not found to act as moderators in both the high scoring and low scoring groups. Thus, the three-way interaction, if any, was weak.

\section{Threats to Validity}

Three specific threats to validity should be kept in mind when interpreting the results of this study. The first is a threat to the statistical conclusion validity of this study, extraneous variance in the experimental setting (Shadish, Cook, \& Campbell, 2002). The 
design of this study allowed individuals to participate online from the location of their choice. Although this design made it possible for a large number of individuals to participate within a short period of time, it resulted in the absence of a controlled experimental setting. Individuals that accessed the study from their home computer may have been listening to music, watching television, or talking on the phone while they read through the scenario and responded to the accompanying questionnaire. These environmental distractions could have affected participants' responses on the items and resulted in inaccurate findings. One way to correct for this threat is to conduct this study in the lab rather than online. This would make it easier to control for extraneous variables across administrations of the study.

The second is a threat to the external validity of this study, interaction of the causal relationship with units (Shadish et al., 2002). This threat is especially applicable to the results that suggested that the type of disability accommodated does not influence individuals' fairness perceptions of the accommodation. This finding may be due to the fact that the majority of participants were psychology majors. As psychology majors, these individuals may have had a unique insight and understanding of psychological disorders, which in turn may have made them more accepting of accommodations made for individuals suffering from major depressive disorder. One way to correct for this threat is to sample individuals across majors.

The third is another threat to the statistical conclusion validity of this study, heterogeneity of units (Shadish et al., 2002). Due to the fact that this was an online study, certain individual characteristics were particularly desirable for participants to possess. A participant's level of discipline, focus, perseverance, and preciseness may have affected 
the quality of the data that they provided, and this in turn, may have influenced the likelihood that significant results would be found. As previously stated, conscientiousness was thought to be an individual characteristic that could affect the chance that the moderating effects of individual characteristics on the relationship between procedural justice and fairness perceptions of accommodations made for employees with disabilities would be detectable. A hierarchical regression was used to test this line of thinking. As presented in Appendix 8, the three-way interactions between conscientiousness, the presence of procedural justice, and one individual characteristics (emotional stability) was found to be statistically significant at an alpha level of .01. Although these results indicate that conscientiousness plays a role in the moderating effect of individual characteristics on the relationship between the presence of procedural justice and fairness perceptions of accommodations made for employees with disabilities, further analyses did not provide a clear conclusion on the impact of specific levels of conscientiousness on this relationship. An additional consideration is the comparability of the four groups. Due to differences in employment status and age across the four groups and the correlation between employment status and age, employment status was a covariate in all regressions and age was a covariate for analyses that only included employed participants. In future research, random assignment to conditions should be used to account for these differences.

Future Research

ln addition to examining the relationship between procedural justice and fairness perceptions of accommodations made for employees with disabilities and potential moderators of this relationship, this study attempted to foster ideas for future research. 
Future studies on the relationship between procedural justice and fairness perceptions of accommodations may examine aspects of the job as potential moderators of this relationship. Aspects of the job that could be examined include whether or not employees work in teams or individually and whether those that work in teams are evaluated based on their individual or team performance. An additional area of future research is how the culture and climate of an organization plays a role in the development of positive relationships between individuals and their coworkers with disabilities.

\section{Implications \& Conclusion}

In conclusion, results from this study suggest that the presence of procedural justice is the main criteria that people use to determine whether or not accommodations made for coworkers with disabilities were determined in the fairest way possible. Results also suggest that although the type of disability that an employee suffers from may affect the quality of relationship that they develop with their coworker, findings from this study do not indicate that the type of disability impacts fairness judgments of accommodations made for them. Even though accommodations are generally viewed favorably, it is important that organizations incorporate procedural justice rules when determining appropriate accommodations. This is especially relevant when the accommodations will directly affect non-disabled coworkers. Additionally, the main effect of agreeableness, conscientiousness, emotional stability, self-esteem, and emotional intelligence should be taken into consideration. Organizations that wish to improve the relationship between individuals with disabilities and non-disabled coworkers should take care to use procedural justice rules when determining appropriate accommodations for those that have requested them. 
Adams, J. S. (1965). Inequity in social exchange. In L. Berkowitz (Ed.), Advances in experimental psychology (Vol. 2, pp. 267-299). New York: Academic Press.

Avery, D. R. (2003). Personality as a predictor of the value of voice. The Journal of Psychology, 137, 435-446.

Barrett-Howard, E., \& Tyler, T. R. (1986). Procedural justice as a criterion in allocation decisions. Journal of Personality and Social Psychology, 2, 296-304.

Barrick, M. R., \& Mount, M. K. (1991). The Big Five personality dimensions and job performance: A meta-analysis. Personnel Psychology, 44, 1-26.

Barrick, M. R., Mount, M. K., \& Strauss, J. P. (1993). Conscientiousness and performance of sales representatives: Test of mediating effects of goal setting. Journal of Applied Psychology, 78, 715-722.

Baumeister, R. F., Campbell, J. D., Krueger, J. I., \& Vohs, K. D. (2003). Does high selfesteem cause better performance, interpersonal success, happiness, or healthier lifestyles? Psychological Science in the Public Interest, 4, 1-44.

Bernerth, J. B., Field, H. S., Giles, W. F., \& Cole. M. S. (2006). Perceived fairness in employee selection: The role of applicant personality. Journal of Business and Psychology, 20, 545-563.

Brockner, J., Heuer, L., Siegel, P. A., Wiesenfeld, B., Martin, C., Grover, S., Reed, T., \& Bjorgvinsson, S. (1998). The moderating effect of self-esteem in reaction to voice: Converging evidence from five studies. Journal of Personality and Social Psychology, 75, 394-407.

Cleveland, J. N., Barnes-Farrell, J. L., \& Ratz, J. M. (1997). Accommodations in the workplace. Human Resource Management Review, 7, 77-108.

Colbert, A. E., Mount, M. K., Harter, J. K., Witt, L. A., \& Barrick, M. R. (2004). Interactive effects of personality and perceptions of the work situation on workplace deviance. Journal of Applied Psychology, 89, 599-609.

Colella, A. (2001). Coworker distributive fairness judgments of the workplace accommodation of employees with disabilities. Academy of Management, 25, 100-116.

Colella, A., Paetzold, R. L., \& Belliveau, M. A. (2004). Factors affecting coworkers' procedural justice inferences of the workplace accommodations of employees with disabilities. Personnel Psychology, 57, 1-23. 
Costa, P. T., Jr., \& McCrae, R. R. (1992). Revised NEO Personality Inventory (NEO-PI$R$ ) and NEO Five-Factor Inventory (NEO-FFI) professional manual. Odessa, FL: Psychological Assessment Resources.

Davies, M., Stankov, L., \& Roberts, R. D. (1998). Emotional intelligence: In search of an elusive construct. Journal of Personality and Social Psychology, 75, 989-1015.

Deutsch, M. (1975). Equity, equality, and need: What determines which values will be used as the basis of distributive justice? Journal of Social Issues, 31, 137-149.

Dineen, B. R., Noe, R. A., \& Wang, C. (2004). Perceived fairness of web-based applicant screening procedures: Weighing the rules of justice and the role of individual differences. Human Resource Management, 43, 127-145.

Folger, R., \& Konovsky, M. A. (1989). Effects of procedural and distributive justice on reactions to pay raise decision. Academy of Management Journal, 32, 115-130.

George, D., \& Mallery, P. (2008). SPSS for Windows step by step: A simple guide and reference 15.0 update. Boston, MA: Pearson Education, Inc.

Goldstein, K. M., \& Blackman, S. (1975). Generalizations of regarding deviant groups. Psychological Reports, 27, 278.

Gouvier, W. D., Steiner, D. D., Jackson, W. T., Schlater, D., \& Rain, J. (1991). Employment discrimination against handicapped job applicants: An analog study of the effects of neurological causation, visibility of handicap, and public contact. Rehabilitation Psychology, 36, 121-129.

Greenberg, J. (1988). Equity and workplace status: A field experiment. Journal of Applied Psychology, 73, 606-613.

Harter, S. (1990). Causes, correlates, and the functional role of global self-worth: A lifespan perspective. In R. Sternberg \& J. Kolligan, Jr. (Eds.), Competence considered (pp. 67-97). New Haven, CT: Yale University Press.

Jones, E. E., Farina, A., Hastorf, A. H., Markus, H., Miller, D. T., Scott, R. A., \& de Sales-French, R. (1984). Social Stigma: The psychology of marked relationships. San Francisco: W. H. Freeman \& Co.

Law, K. S., Wong, C. S., \& Song, L. J. (2004). The construct and criterion validity of emotional intelligence and its potential utility for management studies. Journal of Applied Psychology, 89, 483-496. 
Lind, E. A., Kanfer, R., \& Earley, P. C. (1990). Voice, control, and procedural justice: Instrumental and noninstrumental concerns in fairness judgments. Journal of Personality and Social Psychology, 75, 1-22.

Lind, E. A., \& Tyler, T. R. (1988). The social psychology of procedural justice. New York: Plenum.

Mandell, B., \& Pherwani, S. (2003). Relationship between emotional intelligence and transformational leadership style: A gender comparison. Journal of Business and Psychology, 17, 387-404.

Masterson, S. S., Lewis, K., Goldman, B. M., \& Taylor, M. S. (2000). Integrating justice and social exchange: The differing effects of fair procedures and treatment on work relationships. Academy of Management Journal, 43, 738-748.

Mayer, J. D., Salovey, P., \& Caruso, D. (2000). Models of emotional intelligence. In R. J. Sternberg (Ed.), Handbook of Intelligence. Cambridge: Cambridge University Press.

McFarlin, D. B., Song, J., \& Sonntag, M. (1991). Integrating the disabled into the workforce: A survey of Fortune 500 company attitudes and practices. Employee Responsibilities and Rights Journal, 4, 107-123.

Meyerowitz, B. E., Williams, J. G., \& Gessner, J. (1987). Perceptions of controllability and attitudes towards cancer and cancer patients. Journal of Applied Social Psychology, 17, 471-492.

Moorman, R. H. (1991). Relationship between organizational justice and organizational citizenship behaviors: Do fairness perceptions influence employee citizenship? Journal of Applied Psychology, 76, 845-855.

Myers, D. G. (2002). Exploring Psychology, Fifth Edition. New York: Worth Publishers.

Myyry, L., \& Helkama, K. (2002). Moral reasoning and the use of procedural justice rules in hypothetical and real-life dilemmas. Social Justice Research, 15, 373-391.

Nacoste, R. W. (1987). Social psychology and affirmative action: The importance of process in policy analysis. Journal of Social Issues, 43, 127-132.

Petrides, K. V., \& Furnham, A. (2000). Gender differences in measured and selfestimated trait emotional intelligence. Sex Roles, 42, 449-461.

Raymark, P., Schmit, M., \& Guion, R. (1997). Identifying potentially useful personality constructs for employee selection, Personnel Psychology, 50, 723-736. 
Rosenberg, M. (1965). Society and the adolescent self-image. Princeton, NJ: Princeton University.

Shadish, W. R., Cook, T. D., \& Campbell, D. T. (2002). Experimental and quasiexperimental designs for generalized causal inference. Boston, MA: Houghton Mifflin Company.

Sinha, A. K., \& Jain, A. K. (2004). Emotional Intelligence: Imperative for the organizationally relevant outcomes. Psychological Studies, 49(2-3), 51-96.

Skarlicki, D. P., Folger, R., \& Tesluk, P. (1999). Personality as a moderator in the relationship between fairness and retaliation. Academy of Management Journal, $42,100-108$.

Stoddard, S., Jans, L., Ripple, J. \& Kraus, L. (1998). Chartbook on Work and Disability in the United States, 1998. An InfoUse Report. Washington, D.C.: U.S. National Institute on Disability and Rehabilitation Research.

Stone, E. F., \& Colella, A. (1996). A model of factors affecting the treatment of disabled individuals in orgamizations. Academy of Management: The Academy of Management Review, 21, 352-399.

Stone, E. F., Stone, D. L., \& Dipboye, R. L. (1992). Stigmas in organizations: Race, handicaps, and physical unattractiveness. In K. Kelley (Ed.), Issues, theory, and research in industrial and organizational psychology (pp. 385-444). Amsterdam, The Netherlands: Elsevier.

Stone-Romero, E. F., Stone, D. L., \& Lukaszewski, K. (2006, May). Culture and roletaking by people with disabilities in organizations. In A. Colella (Chair), Potentially negative effects of corporate culture on people with disabilities. Symposium conducted at the meeting of the Society for Industrial and Organizational Psychology, Dallas, TX.

Tafarodi, R. W., \& Vu, C. (1997). Two-dimensional self-esteem and reactions to success and failure. Personality and Social Psychology Bulletin, 23, 626-635.

Tyler, T. R. (1988). What is procedural justice? Criteria used by citizens to assess the fairness of legal procedures. Law and Society Review, 22, 301-355.

Tyler, T. R., \& Smith, H. J. (1998). Social justice and social movements. In D. T. Gilbert, S. T. Fiske, \& G. Lindzey (Eds.). The Handbook of Social Psychology, $4^{\text {th }}$ Edition, vol. 2 (pp. 595-629). New York: McGraw-Hill. 
U.S. Census Bureau, Systems Support Division (2006, March). United States Census 2000. Retrieved July 30, 2006, from http://www.census.gov/main/www/cen2000.html.

U.S. Equal Employment Opportunity Commission (2006, May). Disability discrimination. Retrieved June 25, 2006, from http://www.eeoc.gov/types/ada.html.

Viswesvaran, C., \& Ones, D. S. (2004). Importance of perceived personnel selection system fairness determinants: Relations with demographic, personality, and job characteristics. International Journal of Selection and Assessment, 12, 172-186.

Weiner, B., Perry, R., \& Magnusson, J. (1966). An attributional analysis of reactions to stigmas. Journal of Personality and Social Psychology, 55, 738-748.

Wiesenfeld, B., Swann, W., Brockner, J., \& Bartel, C. (2007). Is more fairness always preferred? Self-esteem moderates reactions to procedural justice. Academy of Management Journal, 50, 1235-1253.

Wong, C., \& Law, K. S. (2002). The effects of leader and follower emotional intelligence on performance and attitude: An exploratory study. The Leadership Quarterly, 13, 243-274.

Zweig, D. \& Webster, J. (2003). Personality as a moderator of monitoring acceptance. Computers in Human Behavior, 19, 479-493. 


\section{Appendices}

Appendix 1: Intercorrelations Between Individual Characteristics and Fairness Perceptions Presented by Wave

Wave 1 (Procedural Justice-Physical Disability)

\begin{tabular}{|c|c|c|c|c|c|c|c|c|c|c|c|c|c|}
\hline & $\mathrm{M}$ & SD & 1 & 2 & 3 & 4 & 5 & 6 & 7 & 8 & 9 & 10 & 11 \\
\hline 1. Fairness Rating & 4.29 & .61 & - & & & & & & & & & & \\
\hline 2. Agreeableness & 3.89 & .49 & .16 & - & & & & & & & & & \\
\hline 3. Conscientiousness & 3.99 & .62 & $.21^{*}$ & $.35^{* *}$ & - & & & & & & & & \\
\hline 4. Emotional Stability & 2.26 & .64 & -.19 & $-.39 * *$ & $-.53 * *$ & - & & & & & & & \\
\hline 5. Self-esteem & 4.11 & .54 & .16 & $.30 * *$ & $.64 * *$ & $-.76 * *$ & - & & & & & & \\
\hline 6. Emotional & 5.67 & .76 & .13 & $.39 * *$ & $.59 * *$ & $-.55 * *$ & $.59 * *$ & - & & & & & \\
\hline Intelligence & & & & & & & & & & & & & \\
\hline 7. Gender ${ }^{a}$ & 0.76 & .43 & -.05 & .14 & .09 & -.03 & .07 & .07 & - & & & & \\
\hline 8. Age & 22.06 & 5.87 & -.06 & .07 & .06 & -.004 & .03 & .09 & -.09 & - & & & \\
\hline 9. Hispanic Origin ${ }^{b}$ & 0.46 & .21 & .004 & -.02 & .09 & -.04 & -.02 & .02 & -.05 & .13 & - & & \\
\hline 10. Employment ${ }^{\mathrm{c}}$ & 0.50 & .25 & .08 & -.06 & .04 & .03 & -.05 & .09 & $-.23 *$ & -.06 & .04 & - & \\
\hline 11. Disability ${ }^{\mathrm{d}}$ & 0.48 & .23 & -.01 & .07 & -.04 & -.03 & -.01 & .14 & .01 & -.05 & .06 & .01 & - \\
\hline
\end{tabular}

$\mathrm{N}=94$

${ }^{\mathrm{a}}$ Dummy coded: $0=$ male, $1=$ female; ${ }^{\mathrm{b}}$ Dummy coded: $0=$ Hispanic, $1=$ non-Hispanic; ${ }^{\mathrm{c}}$ Dummy coded: $0=$ employed $1=$ unemployed; ${ }^{\mathrm{d}}$ Dummy coded: $0=$ yes, $1=$ no.

$* \mathrm{p}<.05, * * \mathrm{p}<.01$. 
Wave 2 (Procedural Justice- Psychological Disorder)

\begin{tabular}{|c|c|c|c|c|c|c|c|c|c|c|c|c|c|}
\hline & $\mathrm{M}$ & SD & 1 & 2 & 3 & 4 & 5 & 6 & 7 & 8 & 9 & 10 & 11 \\
\hline 1. Fairness Rating & 4.23 & .54 & & & & & & & & & & & \\
\hline 2. Agreeableness & 3.81 & .48 & $.35^{* *}$ & - & & & & & & & & & \\
\hline 3. Conscientiousness & 3.86 & .59 & $.40 * *$ & $.34 * *$ & - & & & & & & & & \\
\hline 4. Emotional Stability & 2.17 & .67 & $-.21 *$ & $-.30 * *$ & $-.37 * *$ & - & & & & & & & \\
\hline 5. Self-esteem & 4.15 & .53 & $.33^{* *}$ & $.22 * *$ & $.52 * *$ & $-.75 * *$ & - & & & & & & \\
\hline 6. Emotional & 5.66 & .63 & $.35^{* *}$ & $.30^{*}$ & $.56^{* *}$ & $-.62 * *$ & $.66^{* *}$ & - & & & & & \\
\hline Intelligence & & & & & & & & & & & & & \\
\hline 7. Gender ${ }^{a}$ & 0.73 & .45 & .13 & .14 & .02 & .08 & -.05 & -.01 & - & & & & \\
\hline 8. Age & 22.90 & 5.36 & .04 & .10 & .06 & -.12 & .12 & .05 & -.07 & - & & & \\
\hline 9. Hispanic Origin ${ }^{\mathrm{b}}$ & 0.27 & .45 & -.09 & -.11 & $-.25^{*}$ & .06 & -.07 & -.10 & .15 & .11 & - & & \\
\hline 10. Employment ${ }^{c}$ & 0.31 & .46 & $.27 * *$ & -.002 & -.03 & -.10 & .02 & .08 & .11 & -.13 & -.001 & - & \\
\hline 11. Disability ${ }^{\mathrm{d}}$ & 0.65 & .48 & .002 & .16 & -.11 & -.07 & -.06 & -.11 & -.11 & -.02 & .06 & -.12 & - \\
\hline
\end{tabular}

$\mathrm{N}=96$

${ }^{\mathrm{a}}$ Dummy coded: $0=$ male, $1=$ female; ${ }^{\mathrm{b}}$ Dummy coded: $0=$ Hispanic, $1=$ non-Hispanic $;{ }^{\mathrm{c}}$ Dummy coded: $0=$ employed $1=$ unemployed; ${ }^{\mathrm{d}}$ Dummy coded: $0=$ yes, $1=$ no.

$* \mathrm{p}<.05,{ }^{* *} \mathrm{p}<.01$. 
Wave 3 (No Procedural Justice- Physical Disability)

\begin{tabular}{|c|c|c|c|c|c|c|c|c|c|c|c|c|c|}
\hline & $\mathrm{M}$ & SD & 1 & 2 & 3 & 4 & 5 & 6 & 7 & 8 & 9 & 10 & 11 \\
\hline 1. Fairness Rating & 4.16 & .58 & - & & & & & & & & & & \\
\hline 2. Agreeableness & 3.95 & .48 & .12 & - & & & & & & & & & \\
\hline 3. Conscientiousness & 4.00 & .60 & .06 & 188 & - & & & & & & & & \\
\hline 4. Emotional Stability & 2.17 & .60 & -.11 & $-.35 * *$ & $-.42 * *$ & - & & & & & & & \\
\hline 5. Self-esteem & 4.16 & .45 & .12 & .19 & $.59 * *$ & $-.74 * *$ & - & & & & & & \\
\hline $\begin{array}{l}\text { 6. Emotional } \\
\text { Intelligence }\end{array}$ & 5.73 & .72 & .18 & $.32 * *$ & $.50 * *$ & $-.63 * *$ & $.68^{* *}$ & - & & & & & \\
\hline 7. Gender ${ }^{\mathrm{a}}$ & 0.73 & .45 & .05 & $.23^{*}$ & $.19^{*}$ & -.09 & .04 & .05 & - & & & & \\
\hline 8. Age & 20.85 & 4.29 & $-.19 *$ & -.08 & -.05 & .05 & .04 & -.004 & -.11 & - & & & \\
\hline 9. Hispanic Origin ${ }^{b}$ & 0.23 & .42 & .011 & -.10 & .02 & .03 & -.05 & -.02 & -.03 & .02 & - & & \\
\hline 10. Employment ${ }^{\mathrm{c}}$ & 0.36 & .48 & .04 & .04 & .003 & -.14 & .09 & .14 & -.02 & -.17 & -.04 & - & \\
\hline 11. Disability ${ }^{\mathrm{d}}$ & 0.66 & .48 & .12 & -.07 & -.10 & -.08 & .04 & -.02 & .06 & -.04 & .06 & -.04 & - \\
\hline
\end{tabular}

$\mathrm{N}=107$

${ }^{\mathrm{a}}$ Dummy coded: $0=$ male, $1=$ female; ${ }^{\mathrm{b}}$ Dummy coded: $0=$ Hispanic, $1=$ non-Hispanic; ${ }^{\mathrm{c}}$ Dummy coded: $0=$ employed $1=$ unemployed; ${ }^{\mathrm{d}}$ Dummy coded: $0=$ yes, $1=$ no.

${ }^{*} \mathrm{p}<.05,{ }^{* *} \mathrm{p}<.01$. 
Wave 4 (No Procedural Justice- Psychological Disorder)

\begin{tabular}{|c|c|c|c|c|c|c|c|c|c|c|c|c|c|}
\hline & $\mathrm{M}$ & $\mathrm{SD}$ & 1 & 2 & 3 & 4 & 5 & 6 & 7 & 8 & 9 & 10 & 11 \\
\hline 1. Fairness Rating & 4.12 & .60 & - & & & & & & & & & & \\
\hline 2. Agreeableness & 3.86 & .56 & .18 & - & & & & & & & & & \\
\hline 3. Conscientiousness & 3.85 & .59 & .07 & $.46^{* *}$ & - & & & & & & & & \\
\hline 4. Emotional Stability & 2.33 & .72 & -.11 & $-.42 * *$ & $-.43 * *$ & - & & & & & & & \\
\hline 5. Self-esteem & 3.97 & .58 & .07 & $.34^{* *}$ & $.56^{* *}$ & $-.77 * *$ & - & & & & & & \\
\hline $\begin{array}{l}\text { 6. Emotional } \\
\text { Intelligence }\end{array}$ & 5.55 & .72 & .04 & $.59 * *$ & $.63^{* *}$ & $-.69 * *$ & $.63^{* *}$ & - & & & & & \\
\hline 7. Gender ${ }^{\mathrm{a}}$ & 0.72 & .45 & .10 & .11 & .14 & .13 & -.05 & .03 & - & & & & \\
\hline 8. Age & 19.13 & 2.63 & -.01 & -.02 & -.04 & -.17 & .09 & .08 & .01 & - & & & \\
\hline 9. Hispanic Origin ${ }^{b}$ & 0.28 & .45 & .06 & .08 & -.05 & -.15 & .13 & .13 & -.04 & $.24^{*}$ & - & & \\
\hline 10. Employment ${ }^{c}$ & 0.53 & .50 & .07 & -.10 & -.15 & .07 & -.06 & -.14 & -.09 & -.15 & .13 & - & \\
\hline 11. Disability ${ }^{\mathrm{d}}$ & 0.67 & .47 & .03 & .06 & .14 & -.10 & .11 & .12 & -.01 & .02 & .07 & .01 & - \\
\hline
\end{tabular}

$$
\mathrm{N}=101
$$

${ }^{\mathrm{a}}$ Dummy coded: $0=$ male, $1=$ female; ${ }^{\mathrm{b}}$ Dummy coded: $0=$ Hispanic, $1=$ non-Hispanic; ${ }^{\mathrm{c}}$ Dummy coded: $0=$ employed $1=$ unemployed; ${ }^{\mathrm{d}}$ Dummy coded: $0=$ yes, $1=$ no.

$* \mathrm{p}<.05, * * \mathrm{p}<.01$. 


\section{Appendix 2: Business Summary Containing Accommodation Scenario and Comprehension Check Items}

\section{As you read the following passage, please imagine that you are an employee of this organization.}

Scenario 1 (six procedural justice rules, severe back pain)

The Florida Insurance Group (FIG) is a medium-sized insurance company that provides hurricane and tornado coverage for homeowners and small business owners throughout Florida. FIG currently has offices in Miami, Orlando, and Tallahassee with plans to build branches in Key West and Gainesville. There are currently one hundred individuals who work for FIG.

Isaac Williams founded FIG in 1999. After graduating from Stanford with a Master's degree in Business Administration, he decided to return to his hometown of Miami to start a business of his own. His parents are restaurateurs, and he remembered the difficulty they had when trying to purchase insurance for their first restaurant. He decided to create an insurance company that catered to individuals who found it difficult to get coverage from larger companies. Williams' main goal for FIG is to provide affordable coverage to consumers on a limited budget. FIG accomplishes this by providing the most coverage for the lowest price possible. Williams is well known for treating his employees with respect and concern, and in return, he is well liked and respected by his employees.

FIG employs a group of well-educated and competent individuals. Ninety percent of employees have at least their Bachelor's degree. FIG makes a point to hire individuals who reflect the diverse racial and ethnic population of Florida. Currently, $56 \%$ of employees are racial and ethnic minorities, with $40 \%$ being of Hispanic origin. Additionally, $85 \%$ of FIG employees are bilingual with most employees speaking Spanish, Portuguese, French, or German.

Besides hiring minorities, FIG provides opportunities for students. Each summer, FIG offers an internship to students from local universities. In this internship, six business students are selected to shadow employees from different departments within the organization. Interns are not only able to observe the tasks performed by certain positions, but are also able to work on parts of special projects. Interns are chosen based on their academic achievement, a brief essay, and letters of recommendation. Individuals that participate in the intern program receive invaluable real world experience.

In addition to the racial and ethnic diversity within the organization, there is a focus on equal opportunity among the genders. Fifty-one percent of FIG employees are women. Additionally, women are well represented in positions of leadership and administration. Forty-two percent of managers are females, which is in contrast to most organizations where only $36 \%$ of managers are females. This may be because FIG has policies and practices which are family-friendly. For example, FIG has a flexible schedule that is especially beneficial for employees who have young children in school or daycare. FIG also provides a substantial amount of time for maternity leave, while still providing job security for women who choose to use it. 
As well as supporting diversity among races, ethnicities, and genders, FIG prides itself on hiring and accommodating individuals with disabilities. FIG uses six guidelines when determining appropriate accommodations: 1 ) the same criteria is used for all employees when determining which employees who request accommodations actually receive them, 2) standard guidelines and criteria provided by the Americans with Disability Act are used to choose appropriate accommodations, 3) information from the employee requesting the accommodation as well as medical and legal consultants is taken into consideration, 4) the impact of accommodations on coworkers is taken into consideration, 5) accommodations reflect the moral and ethical standards of the organization, and 6) formal procedures are used to make corrections or adjustments to ineffective accommodations. FIG currently employs and accommodates five individuals with disabilities, including your coworker who suffers from a severe back condition, one of the most common disabilities. This condition makes it painful to sit and stand for long periods of time, lift heavy objects, and walk long distances. They are often fatigued at work due to back pain that affects their ability to sleep at night. Upon request, FIG used the six guidelines to provide your coworker with an accommodation that gives them an extra day off during the week and allows them to have extra breaks during their shift.

These policies and practices have contributed to FIG's ability to succeed in the face of adversity. Despite having competition from larger insurance companies, such as Allstate and State Farm, FIG has been able to hold a solid share of the market in Florida. The company faced some difficulties during its early years. Just nine months after it was founded, Hurricane Irene hit and caused major flooding in southeast Florida and the Florida Keys. At the time, there were not enough employees to handle the influx of claims. In addition, the strategy used to process claims was inefficient. FIG employees felt very overwhelmed, and often took twice the expected amount of time to process claims. After Hurricane Irene, Williams and his staff developed a more efficient process for handling claims. The adjustments were found to be effective during the next hurricane season, and have contributed to the continuous growth and success of FIG.

Scenario 2 (zero procedural justice rules, severe back pain)

The Florida Insurance Group (FIG) is a medium-sized insurance company that provides hurricane and tornado coverage for homeowners and small business owners throughout Florida. FIG currently has offices in Miami, Orlando, and Tallahassee with plans to build branches in Key West and Gainesville. There are currently one hundred individuals who work for FIG.

Isaac Williams founded FIG in 1999. After graduating from Stanford with a Master's degree in Business Administration, he decided to return to his hometown of Miami to start a business of his own. His parents are restaurateurs, and he remembered the difficulty they had when trying to purchase insurance for their first restaurant. He decided to create an insurance company that catered to individuals who found it difficult to get coverage from larger companies. Williams' main goal for FIG is to provide affordable coverage to consumers on a limited budget. FIG accomplishes this by providing the most coverage for the lowest price possible. Williams is well known for 
treating his employees with respect and concern, and in return, he is well liked and respected by his employees.

FIG employs a group of well-educated and competent individuals. Ninety percent of employees have at least their Bachelor's degree. FIG makes a point to hire individuals who reflect the diverse racial and ethnic population of Florida. Currently, $56 \%$ of employees are racial and ethnic minorities, with $40 \%$ being of Hispanic origin. Additionally, $85 \%$ of FIG employees are bilingual with most employees speaking Spanish, Portuguese, French, or German.

Besides hiring minorities, FIG provides opportunities for students. Each summer, FIG offers an internship to students from local universities. In this internship, six business students are selected to shadow employees from different departments within the organization. Interns are not only able to observe the tasks performed by certain positions, but are also able to work on parts of special projects. Interns are chosen based on their academic achievement, a brief essay, and letters of recommendation. Individuals that participate in the intern program receive invaluable real world experience.

In addition to the racial and ethnic diversity within the organization, there is a focus on equal opportunity among the genders. Fifty-one percent of FIG employees are women. Additionally, women are well represented in positions of leadership and administration. Forty-two percent of managers are females, which is in contrast to most organizations where only $36 \%$ of managers are females. This may be because FIG has policies and practices which are family-friendly. For example, FIG has a flexible schedule that is especially beneficial for employees who have young children in school or daycare. FIG also provides a substantial amount of time for maternity leave, while still providing job security for women who choose to use it.

As well as supporting diversity among races, ethnicities, and genders, FIG prides itself on hiring and accommodating individuals with disabilities. FIG currently employs and accommodates five individuals with disabilities, including your coworker who suffers from a severe back condition, one of the most common disabilities. This condition makes it painful to sit and stand for long periods of time, lift heavy objects, and walk long distances. They are often fatigued at work due to back pain that affects their ability to sleep at night. Upon request, FIG provided your coworker with an accommodation that gives them an extra day off during the week and allows them to have extra breaks during their shift.

These policies and practices have contributed to FIG's ability to succeed in the face of adversity. Despite having competition from larger insurance companies, such as Allstate and State Farm, FIG has been able to hold a solid share of the market in Florida. The company faced some difficulties during its early years. Just nine months after it was founded, Hurricane Irene hit and caused major flooding in southeast Florida and the Florida Keys. At the time, there were not enough employees to handle the influx of claims. In addition, the strategy used to process claims was inefficient. FIG employees felt very overwhelmed, and often took twice the expected amount of time to process claims. After Hurricane Irene, Williams and his staff developed a more efficient process for handling claims. The adjustments were found to be effective during the next hurricane season, and have contributed to the continuous growth and success of FIG.

Scenario 3 (six procedural justice rules, major depressive disorder) 
The Florida Insurance Group (FIG) is a medium-sized insurance company that provides hurricane and tornado coverage for homeowners and small business owners throughout Florida. FIG currently has offices in Miami, Orlando, and Tallahassee with plans to build branches in Key West and Gainesville. There are currently one hundred individuals who work for FIG.

Isaac Williams founded FIG in 1999. After graduating from Stanford with a Master's degree in Business Administration, he decided to return to his hometown of Miami to start a business of his own. His parents are restaurateurs, and he remembered the difficulty they had when trying to purchase insurance for their first restaurant. He decided to create an insurance company that catered to individuals who found it difficult to get coverage from larger companies. Williams' main goal for FIG is to provide affordable coverage to consumers on a limited budget. FIG accomplishes this by providing the most coverage for the lowest price possible. Williams is well known for treating his employees with respect and concern, and in return, he is well liked and respected by his employees.

FIG employs a group of well-educated and competent individuals. Ninety percent of employees have at least their Bachelor's degree. FIG makes a point to hire individuals who reflect the diverse racial and ethnic population of Florida. Currently, $56 \%$ of employees are racial and ethnic minorities, with $40 \%$ being of Hispanic origin. Additionally, $85 \%$ of FIG employees are bilingual with most employees speaking Spanish, Portuguese, French, or German.

Besides hiring minorities, FIG provides opportunities for students. Each summer, FIG offers an internship to students from local universities. In this internship, six business students are selected to shadow employees from different departments within the organization. Interns are not only able to observe the tasks performed by certain positions, but are also able to work on parts of special projects. Interns are chosen based on their academic achievement, a brief essay, and letters of recommendation. Individuals that participate in the intern program receive invaluable real world experience.

In addition to the racial and ethnic diversity within the organization, there is a focus on equal opportunity among the genders. Fifty-one percent of FIG employees are women. Additionally, women are well represented in positions of leadership and administration. Forty-two percent of managers are females, which is in contrast to most organizations where only $36 \%$ of managers are females. This may be because FIG has policies and practices which are family-friendly. For example, FIG has a flexible schedule that is especially beneficial for employees who have young children in school or daycare. FIG also provides a substantial amount of time for maternity leave, while still providing job security for women who choose to use it.

As well as supporting diversity among races, ethnicities, and gender, FIG prides itself on hiring and accommodating individuals with disabilities. FIG uses six guidelines when determining appropriate accommodations: 1 ) the same criteria is used for all employees when determining which employees who request accommodations actually receive them, 2) standard guidelines and criteria provided by the Americans with Disability Act are used to choose appropriate accommodations, 3) information from the employee requesting the accommodation as well as medical and legal consultants is taken 
into consideration, 4) the impact of accommodations on coworkers is taken into consideration, 5) accommodations reflect the moral and ethical standards of the organization, and 6) formal procedures are used to make corrections or adjustments to ineffective accommodations. FIG currently employs and accommodates five individuals with disabilities, including your coworker who suffers from major depressive disorder, one of the most prevalent mood disorders. This condition causes them to show a lack of emotions, have delayed responses, and have thoughts of hopelessness. Your coworker takes antidepressant medication and attends weekly therapy sessions, but still has some difficulties performing their job duties. Upon request, FIG used the six guidelines to provide your coworker with an accommodation that transferred them to a position that provides a more flexible schedule, more supervision and support from management, and fewer time-sensitive tasks.

These policies and practices have contributed to FIG's ability to succeed in the face of adversity. Despite having competition from larger insurance companies, such as Allstate and State Farm, FIG has been able to hold a solid share of the market in Florida. The company faced some difficulties during its early years. Just nine months after it was founded, Hurricane Irene hit and caused major flooding in southeast Florida and the Florida Keys. At the time, there were not enough employees to handle the influx of claims. In addition, the strategy used to process claims was inefficient. FIG employees felt very overwhelmed, and often took twice the expected amount of time to process claims. After Hurricane Irene, Williams and his staff developed a more efficient process for handling claims. The adjustments were found to be effective during the next hurricane season, and have contributed to the continuous growth and success of FIG.

Scenario 4 (zero procedural justice rules, major depressive disorder)

The Florida Insurance Group (FIG) is a medium-sized insurance company that provides hurricane and tornado coverage for homeowners and small business owners throughout Florida. FIG currently has offices in Miami, Orlando, and Tallahassee with plans to build branches in Key West and Gainesville. There are currently one hundred individuals who work for FIG.

Isaac Williams founded FIG in 1999. After graduating from Stanford with a Master's degree in Business Administration, he decided to return to his hometown of Miami to start a business of his own. His parents are restaurateurs, and he remembered the difficulty they had when trying to purchase insurance for their first restaurant. He decided to create an insurance company that catered to individuals who found it difficult to get coverage from larger companies. Williams' main goal for FIG is to provide affordable coverage to consumers on a limited budget. FIG accomplishes this by providing the most coverage for the lowest price possible. Williams is well known for treating his employees with respect and concern, and in return, he is well liked and respected by his employees.

FIG employs a group of well-educated and competent individuals. Ninety percent of employees have at least their Bachelor's degree. FIG makes a point to hire individuals who reflect the diverse racial and ethnic population of Florida. Currently, $56 \%$ of employees are racial and ethnic minorities, with $40 \%$ being of Hispanic origin. 
Additionally, $85 \%$ of FIG employees are bilingual with most employees speaking Spanish, Portuguese, French, or German.

Besides hiring minorities, FIG provides opportunities for students. Each summer, FIG offers an internship to students from local universities. In this internship, six business students are selected to shadow employees from different departments within the organization. Interns are not only able to observe the tasks performed by certain positions, but are also able to work on parts of special projects. Interns are chosen based on their academic achievement, a brief essay, and letters of recommendation. Individuals that participate in the intern program receive invaluable real world experience.

In addition to the racial and ethnic diversity within the organization, there is a focus on equal opportunity among the genders. Fifty-one percent of FIG employees are women. Additionally, women are well represented in positions of leadership and administration. Forty-two percent of managers are females, which is in contrast to most organizations where only $36 \%$ of managers are females. This may be because FIG has policies and practices which are family-friendly. For example, FIG has a flexible schedule that is especially beneficial for employees who have young children in school or daycare. FIG also provides a substantial amount of time for maternity leave, while still providing job security for women who choose to use it.

As well as supporting diversity among races, ethnicities, and gender, FIG prides itself on hiring and accommodating individuals with disabilities. FIG currently employs and accommodates five individuals with disabilities, including your coworker who suffers from major depressive disorder, one of the most prevalent mood disorders. This condition causes them to show a lack of emotions, have delayed responses, and have thoughts of hopelessness. Your coworker takes antidepressant medication and attends weekly therapy sessions, but still has some difficulties performing their job duties. Upon request, FIG provided your coworker with an accommodation that transferred them to a position that provides a more flexible schedule, more supervision and support from management, and fewer time-sensitive tasks.

These policies and practices have contributed to FIG's ability to succeed in the face of adversity. Despite having competition from larger insurance companies, such as Allstate and State Farm, FIG has been able to hold a solid share of the market in Florida. The company faced some difficulties during its early years. Just nine months after it was founded, Hurricane Irene hit and caused major flooding in southeast Florida and the Florida Keys. At the time, there were not enough employees to handle the influx of claims. In addition, the strategy used to process claims was inefficient. FIG employees felt very overwhelmed, and often took twice the expected amount of time to process claims. After Hurricane Irene, Williams and his staff developed a more efficient process for handling claims. The adjustments were found to be effective during the next hurricane season, and have contributed to the continuous growth and success of FIG.

Please answer the following questions based on the passage that you have just read. When responding, please continue to imagine that you are an employee of this organization. 
1) What industry is Florida Insurance Group in?
a. accounting
b. insurance
c. consulting
d. advertising

2) FIG values:
a. customer service.
b. innovation.
c. diversity.
d. international relations.

3) Besides English, the following languages are spoken by employees of FIG:
a. Spanish.
b. Spanish and French.
c. Spanish, Portuguese, and French.
d. Spanish, Portuguese, French, and German.

4) Which hurricane caused FIG to change their strategy for handling claims?
a. Hurricane Isaac
b. Hurricane Floyd
c. Hurricane Irene
d. Hurricane Andrew

5) What type of disability did your coworker have?
a. major depressive disorder
b. heart disease
c. severe back pain
d. alcoholism 
Please indicate how accurately each statement describes you. Mark only one number for each statement.

6. I am pleased that FIG hires well-educated and highly skilled individuals.

7. FIG hires interns that have the same moral and ethical standards as the organization.

8. I feel that female managers can make a unique contribution to FIG.

9. The same criteria are used for all individuals when determining which FIG employees who request accommodations actually receive them.

10. FIG's flexible work schedule provides employees the opportunity to work while still taking care of familyrelated responsibilities.

11. I am satisfied with the method used to determine accommodations for disabilities at FIG.

12. I believe that it is beneficial to have women in positions of power.

13. FIG has formal procedures in place to make corrections or adjustments to ineffective

accommodations.

14. I am satisfied with the way that summer interns are chosen.

15. I feel that employing individuals from diverse racial and ethnic backgrounds is of benefit to FIG

16. The same criteria are used for all applicants when determining which individuals that apply for the summer internship are actually chosen.

17. I am pleased that my organization makes a point to hire and accommodate individuals with disabilities.

$\begin{array}{ccccc}\begin{array}{c}\text { Strongly } \\ \text { bisagaro: }\end{array} & \text { Disagreo } & \text { Noutral } & \text { Agreo } & \begin{array}{c}\text { Strongly } \\ \text { Aagroo }\end{array} \\ \text { (1) } & \text { (2) } & \text { (3) } & \text { (1) } & \text { (5) } \\ \text { (1) } & \text { (2) } & \text { (3) } & \text { (4) } & \text { (5) } \\ \text { (1) } & \text { (2) } & \text { (3) } & \text { (1) } & \text { (5) } \\ \text { (1) } & \text { (2) } & \text { (3) } & \text { (4) } & \text { (5) }\end{array}$

18. I feel that FIG provided a fair accommodation for my coworker with a severe back pain/major depressive disorder.

19. I think that it benefits FIG to have employees that speak more than one language.

20. Standard guidelines and criteria provided by the

Americans with Disability Act are used to choose

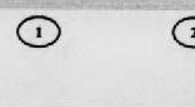

(2)

(3)

(4)

(5)

(1)

(2) (3)

(4)

(3)

(1)

(2)

(1)

(2)

(3)

(.)

(5)

(1)

(3)

(4)

(3)

(1)

(1)

(2)

(3)

(3)

(1)

(2)

(3)

(1) appropriate accommodations.

21. I think that FIG's family-friendly policies make it an attractive organization to work for.

22. The system used by FIG to determine

accommodations for disabilities is a fair one.

23. FIG has formal procedures to reassign dissatisfied interns to a different department.

24. Accommodations made by FIG reflect the organization's moral and ethical standards

\section{The impact of hiring new interns on the workload for} current employees is taken into consideration.

26. The accommodation given to my coworker with severe back pain/major depressive disorder was reasonable.

27. FIG takes information from the employee requesting the accommodation as well as medical and legal consultants into consideration when choosing appropriate accommodations.

28. The use of grades as a major determinant for choosing summer interns is fair. 29. The impact of accommodations on coworkers is taken into consideration. 
Please indicate how accurately each statement describes you. Mark only one number for each statement.

\begin{tabular}{|c|c|c|c|c|c|}
\hline & $\begin{array}{c}\text { Very } \\
\text { Inaccurate }\end{array}$ & Inaccurate. & Neutral & Accurate. & $\begin{array}{l}\text { Very } \\
\text { Accurate }\end{array}$ \\
\hline 1. Have a good word for everyone. & (1) & (2) & (3) & (4) & (5) \\
\hline 2. Believe that others have good intentions. & (1) & (2) & (3) & (4) & (3) \\
\hline 3. Respect others. & (1) & (2) & (3) & (4) & (5) \\
\hline 4. Accept people as they are. & (1) & (2) & (3) & (4) & (5) \\
\hline 5. Make people feel at ease. & (1) & (2) & (3) & (4) & (5) \\
\hline 6. Have a sharp tongue. & (1) & (2) & (3) & (4) & (3) \\
\hline 7. Cut others to pieces. & (1) & (2) & (3) & (4) & (5) \\
\hline 8. Suspect hidden motives in others. & (1) & (2) & (3) & (4) & (5) \\
\hline 9. Get back at others. & (1) & (2) & (3) & (4) & (5) \\
\hline 10. Insult people. & (1) & (2) & (3) & (4) & (5) \\
\hline 11. Am always prepared. & (1) & (2) & (3) & (4) & (5) \\
\hline 12. Pay attention to details. & (1) & (2) & (3) & (4) & (3) \\
\hline 13. Get chores done right away. & (1) & (2) & (3) & (4) & (5) \\
\hline 14. Carry out my plans. & (1) & (2) & (3) & (4) & (3) \\
\hline 15. Make plans and stick to them. & (1) & (2) & (3) & (4) & (5) \\
\hline 16. Waste my time. & (1) & (2) & (3) & (4) & (3) \\
\hline 17. Find it difficult to get down to work & (1) & (2) & (3) & (4) & (5) \\
\hline 18. Do just enough work to get by. & (1) & (2) & (3) & (4) & (5) \\
\hline 19. Don't see things through. & (1) & (2) & (3) & (4) & (5) \\
\hline 20. Shirk my duties. & (1) & (2) & (3) & (4) & (5) \\
\hline 21. Often feel blue. & (1) & (2) & (3) & (4) & (5) \\
\hline 22. Dislike myself. & (1) & (2) & (3) & (4) & (3) \\
\hline 23. Am often down in the dumps. & (1) & (2) & (3) & (4) & (5) \\
\hline 24. Have frequent mood swings. & (1) & (2) & (3) & (4) & (3) \\
\hline 25. Panic easily. & (1) & (2) & (3) & (4) & (5) \\
\hline 26. Rarely get irritated. & (1) & (2) & (3) & (4) & (5) \\
\hline 27. Seldom feel blue. & (1) & (2) & (3) & (4) & (5) \\
\hline 28. Feel com fortable with myself. & (1) & (2) & (3) & (4) & (5) \\
\hline 29. Am not easily bothered by things. & (1) & (2) & (3) & (4) & (5) \\
\hline 30. Am very pleased with myself. & (1) & (2) & (3) & (4) & (5) \\
\hline 31. Feel com fortable with myself. & (1) & (2) & (3) & (4) & (5) \\
\hline 32. Just know that I will be a success. & (1) & (2) & (3) & (4) & (5) \\
\hline 33. Seldom feel blue. & (1) & (2) & (3) & (4) & (5) \\
\hline $\begin{array}{l}\text { 34. Like to take responsibility for making } \\
\text { decisions. }\end{array}$ & & (2) & (3) & (4) & (5) \\
\hline 35. Know my strengths. & (1) & (2) & (3) & (4) & (5) \\
\hline 36. Dislike myself. & (1) & (2) & (3) & (4) & (5) \\
\hline 37. Am less capable than most people. & (1) & (2) & (3) & (4) & (5) \\
\hline 38. Feel that my life lacks direction. & (1) & (2) & (3) & (4) & (5) \\
\hline $\begin{array}{l}\text { 39. Question my ability to do my work } \\
\text { properly. }\end{array}$ & & 1 & (3) & (4) & (5) \\
\hline 40. Feel that I'm unable to deal with things. & (1) & (2) & (3) & (4) & (5) \\
\hline
\end{tabular}




\begin{tabular}{|c|c|c|c|c|c|c|c|}
\hline & $\begin{array}{l}\text { Totally } \\
\text { Disagree }\end{array}$ & Disagree & $\begin{array}{l}\text { Somewhat } \\
\text { Disagree }\end{array}$ & Neutral & $\begin{array}{l}\text { Somewhat } \\
\text { Agree }\end{array}$ & Agree & $\begin{array}{l}\text { Totally } \\
\text { Agree }\end{array}$ \\
\hline $\begin{array}{l}\text { 41. I have a good sense of why I have } \\
\text { certain feelings most of the time. }\end{array}$ & (1) & (2) & (3) & (4) & (5) & (6) & \\
\hline $\begin{array}{l}\text { 42. I have a good understanding of my own } \\
\text { emotions. }\end{array}$ & (1) & (2) & (3) & (4) & (5) & (6) & \\
\hline 43. I really understand what I feel. & (1) & (2) & (3) & (4) & (5) & (6) & \\
\hline $\begin{array}{l}44 \text {. I always know whether or not I am } \\
\text { happy. }\end{array}$ & (1) & (2) & (3) & (4) & (5) & (6) & \\
\hline $\begin{array}{l}\text { 45. I always know my friends' emotions } \\
\text { from their behavior. }\end{array}$ & (1) & (2) & (3) & (4) & (5) & (6) & \\
\hline $\begin{array}{l}\text { 46. I am a good observer of others' } \\
\text { emotions. }\end{array}$ & (1) & (2) & (3) & (4) & (5) & (6) & \\
\hline $\begin{array}{l}\text { 47. I am sensitive to the feelings and } \\
\text { emotions of others. }\end{array}$ & (1) & (2) & (3) & (4) & (5) & (6) & \\
\hline $\begin{array}{l}\text { 48. I have good understanding of the } \\
\text { emotion of people around me }\end{array}$ & (1) & (2) & (3) & (4) & (5) & (6) & \\
\hline $\begin{array}{l}\text { 49. I always set goals for myself and then } \\
\text { try my best to achieve them. }\end{array}$ & (1) & (2) & (3) & (4) & (5) & (6) & \\
\hline $\begin{array}{l}\text { 50. I always tell myself I am a competent } \\
\text { person. }\end{array}$ & (1) & (2) & (3) & (4) & (5) & (6) & \\
\hline 51. I am a self-motivating person. & (1) & (2) & (3) & (4) & (5) & (6) & \\
\hline $\begin{array}{l}52 . \text { I would always encourage myself to try } \\
\text { my best. }\end{array}$ & (1) & (2) & (3) & (4) & (5) & (6) & \\
\hline $\begin{array}{l}53 . \text { I am able to control my temper so that I } \\
\text { can handle difficulties rationally. }\end{array}$ & (1) & (2) & (3) & (4) & (5) & (6) & \\
\hline $\begin{array}{l}\text { 54. I am quite capable of controlling my } \\
\text { own emotions. }\end{array}$ & (1) & (2) & (3) & (4) & (5) & (6) & \\
\hline $\begin{array}{l}55 . \text { I can always calm down quickly when I } \\
\text { am very angry. }\end{array}$ & (1) & (2) & (3) & (4) & (5) & (6) & \\
\hline $\begin{array}{l}\text { 56. I have good control of my own } \\
\text { emotions. }\end{array}$ & (1) & (2) & (3) & (4) & (5) & (6) & \\
\hline
\end{tabular}


Appendix 4: Demographics Questionnaire

Gender

Age

Grade Classification

Race

Hispanic

Currently Employed

Do you have a relative or close

friend with a

If you do have a relative or close

friend with a

disability, what is your

relationship to them?
Male Female

Freshman Sophomore Junior Senior

Yes No

Yes No

Yes No 
Appendix 5: Hierarchical Regression Analyses for Variables Predicting the Fairness Perceptions of Employed Participants

Agreeableness

\begin{tabular}{ll}
\hline \multicolumn{1}{c}{ Variable } & $\beta$ \\
\hline Step 1 & \\
Procedural Justice $(0 / 1)$ & -.07 \\
Age & -.03 \\
$\mathrm{R}^{2}$ & .005 \\
Step 2 & \\
Procedural Justice $(0 / 1)$ & -.09 \\
Age & -.03 \\
Agreeableness & $.18^{* *}$ \\
$\mathrm{R}^{2}$ & $.035^{*}$ \\
$\Delta \mathrm{R}^{2}$ & $.030^{* *}$ \\
Step 3 & \\
Procedural Justice $(0 / 1)$ & -.08 \\
Age & -.04 \\
Agreeableness & $.29^{* *}$ \\
$\mathrm{PJ}_{\mathrm{x}}$ Agreeableness & -.17 \\
$\mathrm{R}^{2}$ & $.049^{*}$ \\
$\Delta \mathrm{R}^{2}$ & .014 \\
\hline
\end{tabular}

${ }^{*} \mathrm{p}<.05,{ }^{* *} \mathrm{p}<.01$.

Conscientiousness

\begin{tabular}{ll}
\hline \multicolumn{1}{c}{ Variable } & $\beta$ \\
\hline Step 1 & \\
Procedural Justice (0/1) & -.07 \\
Age & -.03 \\
$\mathrm{R}^{2}$ & .005
\end{tabular}

Step 2

Procedural Justice $(0 / 1) \quad-.08$

Age

Conscientiousness

$-.02$

$\mathrm{R}^{2}$

$.19^{* *}$

$\Delta \mathrm{R}^{2}$

$.039 *$

$.034^{* *}$

Step 3

Procedural Justice (0/1) $\quad-.08$

Age

$-.03$

Conscientiousness

$.27 * *$

$\mathrm{PJ} \times$ Conscientiousness $\quad-.12$

$\mathrm{R}^{2}$

$.048^{*}$

$\frac{\Delta \mathrm{R}^{2}}{* \mathrm{p}<.05,{ }^{* *} \mathrm{p}<.01 .}$

.009 


\begin{tabular}{lc}
\hline \multicolumn{1}{c}{ Variable } & $\beta$ \\
\hline Step 1 & \\
Procedural Justice (0/1) & -.07 \\
Age & -.03 \\
$\mathrm{R}^{2}$ & .005 \\
Step 2 & \\
Procedural Justice (0/1) & -.07 \\
Age & -.03 \\
Emotional Stability & $-.17^{* *}$ \\
$\mathrm{R}^{2}$ & $.033^{*}$ \\
$\Delta \mathrm{R}^{2}$ & $.028^{* *}$
\end{tabular}

Step 3

Procedural Justice (0/1) $\quad-.07$

Age $\quad-.03$

Emotional Stability $\quad-.22 *$

PJ x Emotional Stability $\quad .07$

$\mathrm{R}^{2} \quad .036$

\begin{tabular}{ll}
$\Delta \mathrm{R}^{2}$ & .003 \\
\hline$* \mathrm{p}<.05, * * \mathrm{p}<.01$. &
\end{tabular}

Self-esteem

\begin{tabular}{ll}
\hline \multicolumn{1}{c}{ Variable } & $\beta$ \\
\hline Step 1 & \\
Procedural Justice $(0 / 1)$ & -.07 \\
Age & -.03 \\
$\mathrm{R}^{2}$ & .005
\end{tabular}

Step 2

Procedural Justice (0/1) $\quad-.07$

Age $\quad-.04$

Self-esteem $\quad .21^{* *}$

$\mathrm{R}^{2} \quad .047^{* *}$

$\Delta \mathrm{R}^{2} \quad .041^{* *}$

Step 3

Procedural Justice (0/1) $\quad-.06$

Age $\quad-.04$

Self-esteem $\quad .25^{* *}$

PJ x Self-esteem $\quad-.07$

$\mathrm{R}^{2} \quad .050^{*}$

\begin{tabular}{cc}
$\Delta \mathrm{R}^{2}$ & .003 \\
\hline$* \mathrm{p}<.05,{ }^{* *} \mathrm{p}<.01$ &
\end{tabular} 


\begin{tabular}{lc}
\hline \multicolumn{1}{c}{ Variable } & $\beta$ \\
\hline Step 1 & \\
Procedural Justice $(0 / 1)$ & -.07 \\
Age & -.03 \\
$\mathrm{R}^{2}$ & .005 \\
Step 2 & \\
Procedural Justice $(0 / 1)$ & -.08 \\
Age & -.03 \\
Emotional Intelligence & $.17^{* *}$ \\
$\mathrm{R}^{2}$ & $.03^{*}$ \\
$\Delta \mathrm{R}^{2}$ & $.03^{* *}$ \\
Step 3 & \\
Procedural Justice $(0 / 1)$ & -.08 \\
Age & -.03 \\
Emotional Intelligence & $.19^{*}$ \\
$\mathrm{PJ}^{2}$ Emotional Intelligence & -.03 \\
$\mathrm{R}^{2}$ & .034 \\
$\Delta \mathrm{R}^{2}$ & .001 \\
\hline${ }^{*} \mathrm{p}<.05,{ }^{* *} \mathrm{p}<.01$. &
\end{tabular}


Appendix 6: Hierarchical Regression Analyses for Factors of Emotional Intelligence Predicting Fairness Perceptions

Self-Emotions Appraisal (SEA)

Variable $\beta$

\begin{tabular}{lc}
\hline Step 1 & \\
& \\
Procedural Justice (0/1) & $-.12^{*}$ \\
Employment (0/1) & .09 \\
Self-Emotions Appraisal (SEA) & $.15^{* *}$ \\
$\mathrm{R}^{2}$ & $.041^{* *}$
\end{tabular}

Step 2

Procedural Justice $(0 / 1) \quad-.12^{*}$

Employment $(0 / 1) \quad .09$

SEA $\quad .17^{*}$

PJ X SEA $\quad-.03$

$\mathrm{R}^{2} \quad .042^{* *}$

\begin{tabular}{lr}
$\Delta \mathrm{R}^{2}$ & .000 \\
\hline$* \mathrm{p}<0.05 * * \mathrm{p}<01$
\end{tabular}

Others-Emotions Appraisal (OEA)

\begin{tabular}{lc}
\hline \multicolumn{1}{c}{ Variable } & $\beta$ \\
\hline Step 1 & \\
Procedural Justice (0/1) & $-.12^{*}$ \\
Employment (0/1) & $.10^{*}$ \\
Others-Emotions Appraisal (OEA) & $.16^{* *}$ \\
$\mathrm{R}^{2}$ & $.046^{* *}$
\end{tabular}

Step 2

Procedural Justice $(0 / 1) \quad-.12^{* *}$

Employment $(0 / 1) \quad .11^{* *}$

OEA $.15^{*}$

PJ x OEA $\quad .02$

$\mathrm{R}^{2} \quad .046^{* *}$

\begin{tabular}{ll}
$\Delta \mathrm{R}^{2}$ & .000 \\
\hline$* \mathrm{p}<.05 * * \mathrm{p}<.01$ &
\end{tabular} 


\begin{tabular}{lc}
\hline \multicolumn{1}{c}{ Variable } & $\beta$ \\
\hline Step 1 & $-.11^{*}$ \\
Procedural Justice $(0 / 1)$ & $.10^{*}$ \\
Employment $(0 / 1)$ & $.11^{*}$ \\
Use of Emotion (UOE) & $.032^{* *}$ \\
$\mathrm{R}^{2}$ & \\
Step 2 & $-.11^{*}$ \\
Procedural Justice $(0 / 1)$ & .10 \\
Employment $(0 / 1)$ & $.18^{*}$ \\
UOE & -.09 \\
PJ $\mathrm{x}$ UOE & $.035^{*}$ \\
$\mathrm{R}^{2}$ & .003 \\
$\Delta \mathrm{R}^{2}$ & \\
\hline$* \mathrm{p}<.05,{ }^{* *} \mathrm{p}<.01$. &
\end{tabular}

Regulation of Emotion (ROE)

\begin{tabular}{lc}
\hline \multicolumn{1}{c}{ Variable } & $\beta$ \\
\hline Step 1 & $-.12^{*}$ \\
Procedural Justice (0/1) & $.10^{*}$ \\
Employment (0/1) & .05 \\
Regulation of Emotion (ROE) & $.023^{*}$ \\
$\mathrm{R}^{2}$ &
\end{tabular}

Step 2

\begin{tabular}{lc} 
Procedural Justice & $-.12^{*}$ \\
Employment $(0 / 1)$ & $.10^{*}$ \\
$\mathrm{ROE}$ & .10 \\
$\mathrm{PJ} \times \mathrm{ROE}$ & -.06 \\
$\mathrm{R}^{2}$ & $.025^{*}$ \\
$\Delta \mathrm{R}^{2}$ & .002 \\
\hline
\end{tabular}

$* \mathrm{p}<.05$. 
Appendix 7: T test Comparisons for Men and Women on Emotional Intelligence

\begin{tabular}{lccc}
\hline Condition & Men & Women & t-value \\
\hline 1 & $5.46(.87)$ & $5.60(.72)$ & -.640 \\
& $\mathrm{~N}=23$ & $\mathrm{~N}=71$ & \\
2 & $5.69(.68)$ & $5.67(.59)$ & .124 \\
& $\mathrm{~N}=26$ & $\mathrm{~N}=69$ & \\
3 & $5.67(.83)$ & $5.75(.68)$ & -.523 \\
& $\mathrm{~N}=29$ & $\mathrm{~N}=78$ & \\
4 & $5.52(.73)$ & $5.56(.71)$ & -.265 \\
& $\mathrm{~N}=29$ & $\mathrm{~N}=73$ & \\
Total & $5.59(.77)$ & $5.64(.68)$ & -.680 \\
& $\mathrm{~N}=107$ & $\mathrm{~N}=291$ & \\
\hline
\end{tabular}


Appendix 8: Hierarchical Regression Analyses for Three-way Interaction Between Conscientiousness. Individual Characteristics, and Procedural Justice

Agreeableness

\begin{tabular}{lc}
\hline \multicolumn{1}{c}{ Variable } & $\beta$ \\
\hline Step 1 & $-.13^{* *}$ \\
Procedural Justice $(0 / 1)$ & $.11^{*}$ \\
Employment $(0 / 1)$ & $.15^{* *}$ \\
Agreeableness & $.13^{*}$ \\
Conscientiousness & $.073^{* *}$ \\
$\mathrm{R}^{2}$ & \\
Step 2 & $-.13^{* *}$ \\
Procedural Justice $(0 / 1)$ & $.11^{*}$ \\
Employment $(0 / 1)$ & $.18^{*}$ \\
Agreeableness & $.23^{* *}$ \\
Conscientiousness & -.03 \\
PJ x Agreeableness & $-.14^{*}$ \\
PJ x Conscientiousness & .03 \\
Agreeableness x Conscientiousness & $.085^{* *}$ \\
$\mathrm{R}^{2}$ & .012 \\
$\Delta$ R ${ }^{2}$ & \\
Step 3 & $-.12^{*}$ \\
Procedural Justice $(0 / 1)$ & $.11^{*}$ \\
Employment $(0 / 1)$ & $.18^{*}$ \\
Agreeableness & $.24^{* *}$ \\
Conscientiousness & -.03 \\
PJ x Agreeableness & $-.15^{*}$ \\
PJ x Conscientiousness & .05 \\
Agreeableness x Conscientiousness & -.03 \\
PJ x Agreeableness x Conscientiousness & $.085^{* *}$ \\
$\mathrm{R}^{2}$ & .000 \\
$\Delta$ R ${ }^{2}$ & $-.13^{* *}$ \\
\hline
\end{tabular}

${ }^{*} \mathrm{p}<.05,{ }^{* *} \mathrm{p}<.01$. 


\section{Variable}

Step 1

Procedural Justice (0/1)

$-.12^{*}$

Employment (0/1)

$.11 *$

Emotional Stability

$-.08$

Conscientiousness

$.14^{* *}$

$\mathrm{R}^{2}$

$.058 * *$

Step 2

Procedural Justice $(0 / 1)$

$-.12 *$

Employment (0/1)

$.11^{*}$

Emotional Stability

$-.07$

Conscientiousness

$.27 * *$

PJ x Emotional Stability

$-.03$

$\mathrm{PJ} \times$ Conscientiousness

$-.16^{*}$

Emotional Stability x Conscientiousness

$-.07$

$\mathrm{R}^{2}$

$\Delta \mathrm{R}^{2}$

$.073 * *$

.015

Step 3

Procedural Justice $(0 / 1)$

Employment (0/1)

$-.17 * *$

$.11^{*}$

Emotional Stability

$-.07$

Conscientiousness

$24 * *$

PJ x Emotional Stability

$-.05$

PJ x Conscientiousness

$-.12$

Emotional Stability $\mathrm{x}$ Conscientiousness

.06

PJ $\times$ Emotional Stability $x$ Conscientiousness $\quad-.18^{* *}$

$\mathrm{R}^{2}$

$.087 * *$

$\Delta \mathrm{R}^{2}$

$.015^{* *}$

${ }^{*} \mathrm{p}<.05,{ }^{* *} \mathrm{p}<.01$. 


\begin{tabular}{|c|c|}
\hline Variable & $\beta$ \\
\hline \multicolumn{2}{|l|}{ Step 1} \\
\hline Procedural Justice $(0 / 1)$ & $-.11^{*}$ \\
\hline Employment $(0 / 1)$ & $.11^{*}$ \\
\hline Self-esteem & .09 \\
\hline Conscientiousness & $.13^{*}$ \\
\hline $\mathrm{R}^{2}$ & $.057^{* *}$ \\
\hline \multicolumn{2}{|l|}{ Step 2} \\
\hline Procedural Justice $(0 / 1)$ & $-.11^{*}$ \\
\hline Employment $(0 / 1)$ & $.12^{*}$ \\
\hline Self-esteem & .10 \\
\hline Conscientiousness & $.26 * *$ \\
\hline PJ x Self-esteem & -.01 \\
\hline PJ x Conscientiousness & -.14 \\
\hline Self-esteem $x$ Conscientiousness & $.13^{*}$ \\
\hline $\mathrm{R}^{2}$ & $.082 * *$ \\
\hline$\Delta \mathrm{R}^{2}$ & $.025 *$ \\
\hline \multicolumn{2}{|l|}{ Step 3} \\
\hline Procedural Justice $(0 / 1)$ & $-.15^{* *}$ \\
\hline Employment $(0 / 1)$ & $.11^{*}$ \\
\hline Self-esteem & .09 \\
\hline Conscientiousness & $.24 * *$ \\
\hline PJ x Self-esteem & .01 \\
\hline $\mathrm{PJ} \times$ Conscientiousness & -.11 \\
\hline Self-esteem $\mathrm{x}$ Conscientiousness & .04 \\
\hline PJ x Self-esteem x Conscientiousness & .13 \\
\hline $\mathrm{R}^{2}$ & $.088 * *$ \\
\hline$\Delta \mathrm{R}^{2}$ & .006 \\
\hline
\end{tabular}


Emotional Intelligence

$$
\text { Variable }
$$

$\beta$

Step 1

Procedural Justice (0/1)

$-.12^{*}$

Employment (0/1)

$.11^{*}$

Emotional Intelligence

.08

Conscientiousness

$\mathrm{R}^{2}$

$.14^{*}$

$.056^{* *}$

Step 2

Procedural Justice $(0 / 1)$

Employment (0/1)

$-.12 * *$

$.11^{*}$

Emotional Intelligence

.06

Conscientiousness

$.29 * *$

PJ x Emotional Intelligence

.04

PJ x Conscientiousness

$-.18^{*}$

Emotional Intelligence $\mathrm{x}$ Conscientiousness

$.12^{*}$

$\mathrm{R}^{2}$

$\Delta \mathrm{R}^{2}$

$.081 * *$

$.025^{*}$

Step 3

Procedural Justice $(0 / 1)$

Employment (0/1)

$-.15 * *$

$.11^{*}$

Emotional Intelligence

.06

Conscientiousness

$.27 * *$

$\mathrm{PJ} \times$ Emotional Intelligence

.05

$\mathrm{PJ} \times$ Conscientiousness

$-.16$

Emotional Intelligence $\mathrm{x}$ Conscientiousness $\quad .05$

$\mathrm{PJ} \times$ Emotional Intelligence $\mathrm{x} \quad .10$

Conscientiousness

$\mathrm{R}^{2}$

$\Delta \mathrm{R}^{2}$

.003

${ }^{*} \mathrm{p}<.05,{ }^{* *} \mathrm{p}<.01$. 
Appendix 9: Presentation of Hierarchical Regression Analyses for Three-way Interaction Between Conscientiousness, Individual Characteristics, and Procedural Justice
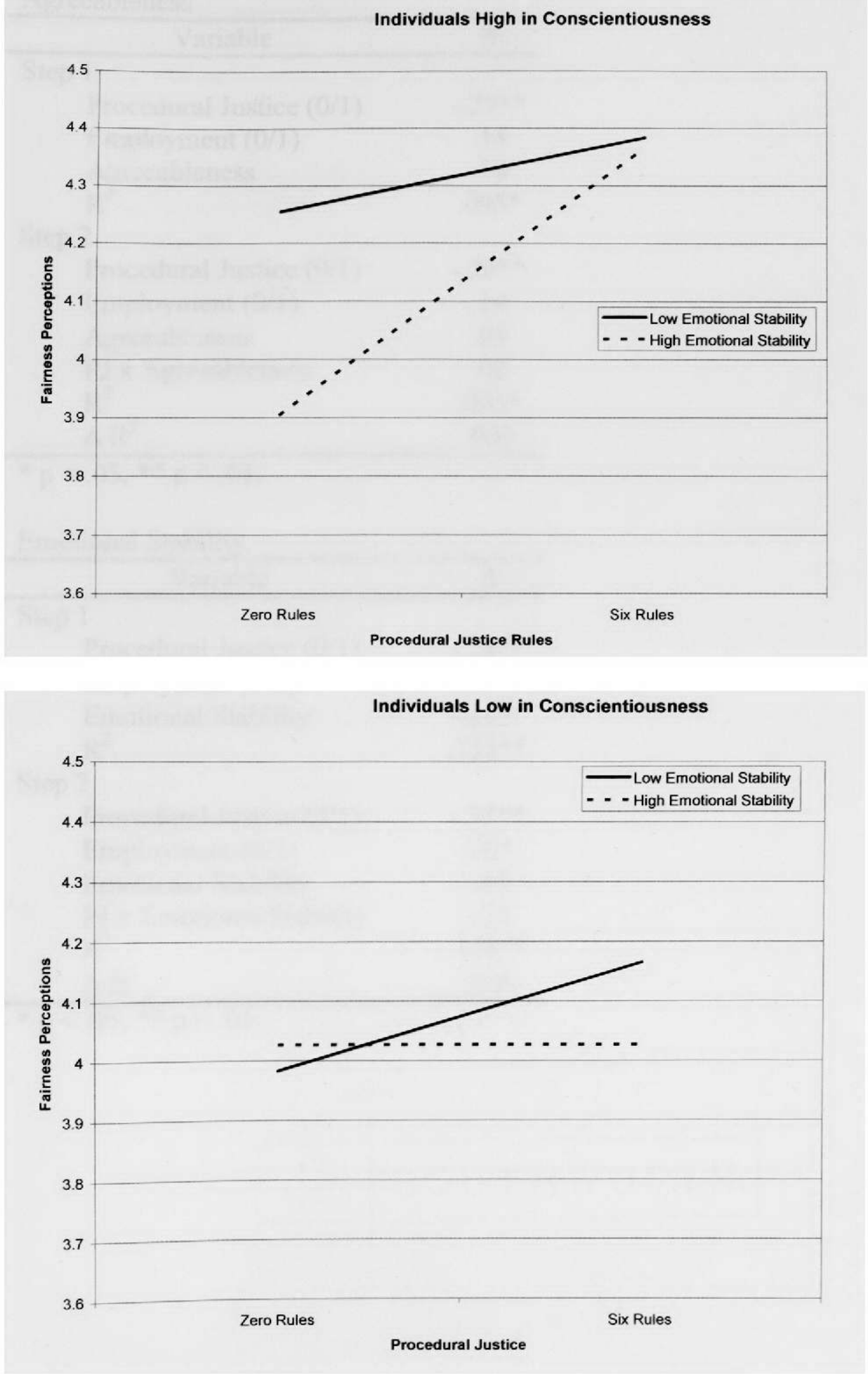
Appendix 10: Hierarchical Regression Analyses for Individual Characteristics Predicting Fairness Perceptions for Individuals High in Conscientiousness

Agreeableness

\begin{tabular}{|c|c|}
\hline Variable & $\beta$ \\
\hline \multicolumn{2}{|l|}{ Step 1} \\
\hline Procedural Justice (0/1) & $-.27 * *$ \\
\hline Employment $(0 / 1)$ & .14 \\
\hline Agreeableness & .10 \\
\hline $\mathrm{R}^{2}$ & $.095 *$ \\
\hline \multicolumn{2}{|l|}{ Step 2} \\
\hline Procedural Justice $(0 / 1)$ & $-.27 * *$ \\
\hline Employment $(0 / 1)$ & .14 \\
\hline Agreeableness & .09 \\
\hline PJ x Agreeableness & .02 \\
\hline $\mathrm{R}^{2}$ & $.095^{*}$ \\
\hline$\Delta \mathrm{R}^{2}$ & .000 \\
\hline \multicolumn{2}{|l|}{${ }^{*} \mathrm{p}<.05,{ }^{* *} \mathrm{p}<.01$} \\
\hline \multicolumn{2}{|l|}{ Emotional Stability } \\
\hline Variable & $\beta$ \\
\hline \multicolumn{2}{|l|}{ Step 1} \\
\hline Procedural Justice (0/1) & $-.28 * *$ \\
\hline Employment $(0 / 1)$ & $.19^{*}$ \\
\hline Emotional Stability & $-.27 * *$ \\
\hline $\mathrm{R}^{2}$ & $.153^{* *}$ \\
\hline \multicolumn{2}{|l|}{ Step 2} \\
\hline Procedural Justice (0/1) & $-.35 * *$ \\
\hline Employment $(0 / 1)$ & $.20^{*}$ \\
\hline Emotional Stability & -.10 \\
\hline PJ x Emotional Stability & -.24 \\
\hline $\mathrm{R}^{2}$ & $.179^{* *}$ \\
\hline$\Delta \mathrm{R}^{2}$ & .026 \\
\hline
\end{tabular}




\begin{tabular}{|c|c|}
\hline Variable & $\beta$ \\
\hline \multicolumn{2}{|l|}{ Step 1} \\
\hline Procedural Justice $(0 / 1)$ & -.25 \\
\hline Employment $(0 / 1)$ & .18 \\
\hline Self-esteem & $.31 * *$ \\
\hline $\mathrm{R}^{2}$ & $.177^{* *}$ \\
\hline \multicolumn{2}{|l|}{ Step 2} \\
\hline Procedural Justice $(0 / 1)$ & $-.33 * *$ \\
\hline Employment $(0 / 1)$ & .18 \\
\hline Self-esteem & .18 \\
\hline PJ x Self-esteem & .19 \\
\hline $\mathrm{R}^{2}$ & $.190^{* *}$ \\
\hline$\Delta \mathrm{R}^{2}$ & .012 \\
\hline \multicolumn{2}{|l|}{${ }^{*} \mathrm{p}<.05,{ }^{* *} \mathrm{p}<.01$} \\
\hline \multicolumn{2}{|l|}{ Emotional Intelligence } \\
\hline Variable & $\beta$ \\
\hline \multicolumn{2}{|l|}{ Step 1} \\
\hline Procedural Justice $(0 / 1)$ & $-.27 * *$ \\
\hline Employment $(0 / 1)$ & .13 \\
\hline Emotional Intelligence & $.23^{*}$ \\
\hline $\mathrm{R}^{2}$ & $.135^{* *}$ \\
\hline \multicolumn{2}{|l|}{ Step 2} \\
\hline Procedural Justice (0/1) & $-.26^{*}$ \\
\hline Employment $(0 / 1)$ & .13 \\
\hline Emotional Intelligence & .25 \\
\hline PJ x Emotional Intelligence & .25 \\
\hline $\mathrm{R}^{2}$ & $.136^{* *}$ \\
\hline$\Delta \mathrm{R}^{2}$ & .000 \\
\hline
\end{tabular}


Appendix 11: Hierarchical Regression Analyses for Individual Characteristics Predicting Fairness Perceptions for Individuals Low in Conscientiousness

Agreeableness

\begin{tabular}{lc}
\hline \multicolumn{1}{c}{ Variable } & $\beta$ \\
\hline Step 1 & .02 \\
Procedural Justice $(0 / 1)$ & .12 \\
Employment $(0 / 1)$ & .17 \\
Agreeableness & .051 \\
$\mathrm{R}^{2}$ & \\
Step 2 & .05 \\
Procedural Justice $(0 / 1)$ & .12 \\
Employment $(0 / 1)$ & .10 \\
Agreeableness & .10 \\
PJ x Agreeableness & .056 \\
$\mathrm{R}^{2}$ & .005 \\
$\Delta \mathrm{R}^{2}$ & \\
\hline & \\
Emotional Stability & $\beta$ \\
\hline \multicolumn{2}{c}{ Variable } \\
Step 1 & .04 \\
Procedural Justice $(0 / 1)$ & .11 \\
Employment $(0 / 1)$ & -.09 \\
Emotional Stability & .030 \\
$\mathrm{R}^{2}$ & \\
Step 2 & .06 \\
Procedural Justice $(0 / 1)$ & .12 \\
Employment $(0 / 1)$ & .24 \\
Emotional Stability & .24 \\
PJ x Emotional Stability & .053 \\
$\mathrm{R}^{2}$ & .023 \\
$\Delta$ R & \\
\hline
\end{tabular}




\begin{tabular}{|c|c|}
\hline Variable & $\beta$ \\
\hline \multicolumn{2}{|l|}{ Step 1} \\
\hline Procedural Justice $(0 / 1)$ & .03 \\
\hline Employment $(0 / 1)$ & .14 \\
\hline Self-esteem & -.02 \\
\hline $\mathrm{R}^{2}$ & .023 \\
\hline \multicolumn{2}{|l|}{ Step 2} \\
\hline Procedural Justice $(0 / 1)$ & -.03 \\
\hline Employment $(0 / 1)$ & .14 \\
\hline Self-esteem & .05 \\
\hline PJ x Self-esteem & -.11 \\
\hline $\mathrm{R}^{2}$ & .028 \\
\hline$\Delta R^{2}$ & .004 \\
\hline \multicolumn{2}{|l|}{ Emotional Intelligence } \\
\hline Variable & $\beta$ \\
\hline \multicolumn{2}{|l|}{ Step 1} \\
\hline Procedural Justice $(0 / 1)$ & .03 \\
\hline Employment $(0 / 1)$ & .14 \\
\hline Emotional Intelligence & -.002 \\
\hline $\mathrm{R}^{2}$ & .023 \\
\hline \multicolumn{2}{|l|}{ Step 2} \\
\hline Procedural Justice (0/1) & -.08 \\
\hline Employment $(0 / 1)$ & .12 \\
\hline Emotional Intelligence & .16 \\
\hline PJ $x$ Emotional Intelligence & -.25 \\
\hline $\mathrm{R}^{2}$ & .044 \\
\hline$\Delta \mathrm{R}^{2}$ & .021 \\
\hline
\end{tabular}

